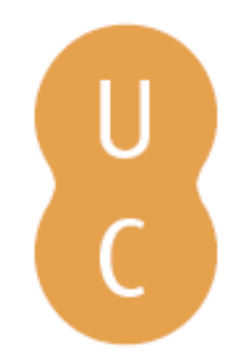

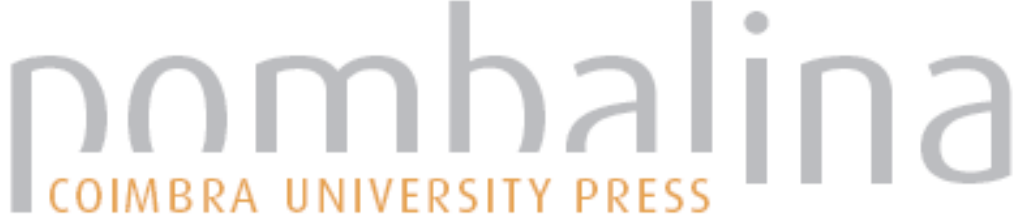

\section{Reestruturação de áreas de influência e de rotas de veículos num sistema de recolha de resíduos recicláveis} \author{
$\begin{array}{ll}\text { Autor(es): } & \text { Ramos, Tânia Rodrigues Pereira; Gomes, Maria Isabel; Póvoa, Ana } \\ \text { Paula Barbosa }\end{array}$ \\ Publicado por: Imprensa da Universidade de Coimbra \\ URL \\ persistente: URI:http://hdl.handle.net/10316.2/35932 \\ DOI: $\quad$ DOI:http://dx.doi.org/10.14195/978-989-26-0738-2_12 \\ Accessed : $\quad$ 26-Apr-2023 14:09:07
}

A navegação consulta e descarregamento dos títulos inseridos nas Bibliotecas Digitais UC Digitalis, UC Pombalina e UC Impactum, pressupõem a aceitação plena e sem reservas dos Termos e Condições de Uso destas Bibliotecas Digitais, disponíveis em https://digitalis.uc.pt/pt-pt/termos.

Conforme exposto nos referidos Termos e Condições de Uso, o descarregamento de títulos de acesso restrito requer uma licença válida de autorização devendo o utilizador aceder ao(s) documento(s) a partir de um endereço de IP da instituição detentora da supramencionada licença.

Ao utilizador é apenas permitido o descarregamento para uso pessoal, pelo que o emprego do(s) título(s) descarregado(s) para outro fim, designadamente comercial, carece de autorização do respetivo autor ou editor da obra.

Na medida em que todas as obras da UC Digitalis se encontram protegidas pelo Código do Direito de Autor e Direitos Conexos e demais legislação aplicável, toda a cópia, parcial ou total, deste documento, nos casos em que é legalmente admitida, deverá conter ou fazer-se acompanhar por este aviso.

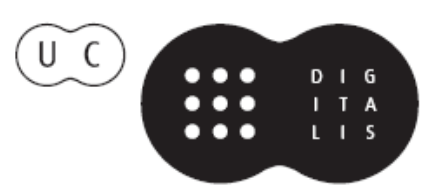




\section{INVESTIGAÇÃO OPERACIONAL EM AÇÃO \\ CASOS DE APLICAÇÃO}

RUI CARVALHO OLIVEIRA JOSÉ SOEIRO FERREIRA (EDITORES)

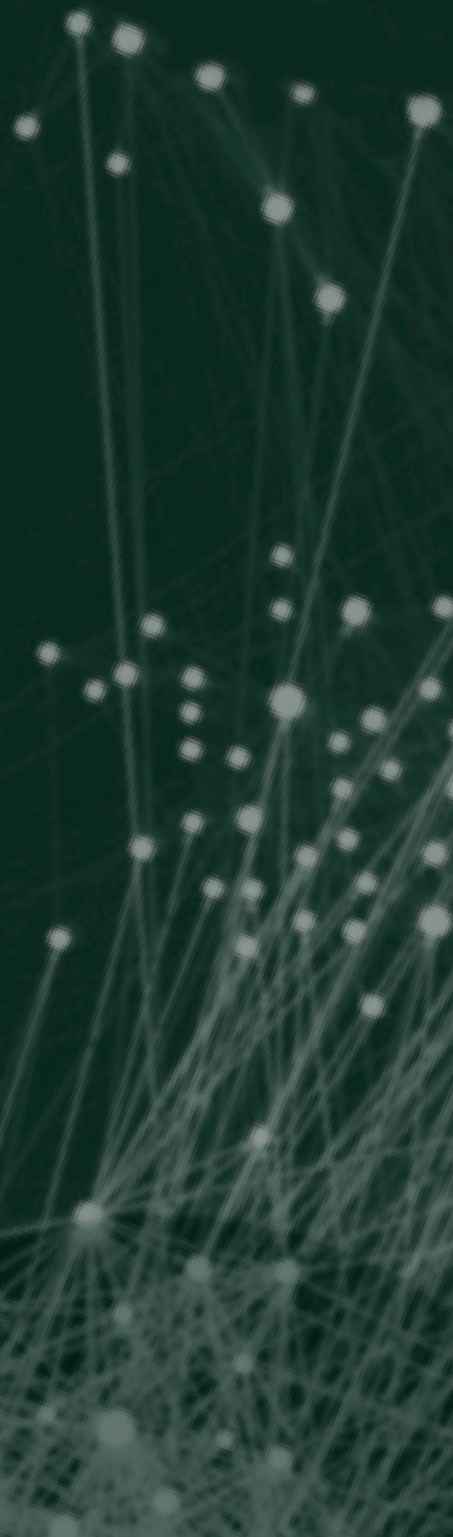




\section{CASO 12}

\section{REESTRUTURAÇÃo de Áreas de INFLUÊNCIA E DE ROTAS DE VEÍCULOS NUM SISTEMA DE RECOLHA DE RESÍDUOS RECICLÁVEIS}

Tânia Rodrigues Pereira Ramos BRU, Instituto Universitário de Lisboa (ISCTE-IUL) tania.ramos@iscte.pt

Maria Isabel Gomes CMA - FCT, Universidade Nova de Lisboa mirg@fct.unl.pt

Ana Paula Barbosa Póvoa

CEG - IST, Instituto Superior Técnico, Universidade de Lisboa apovoa@tecnico.ulisboa.pt 


\section{RESUMO}

Este trabalho versa sobre o planeamento de sistemas logísticos associados à recolha de resíduos recicláveis. Pretende-se definir as áreas de influência de depósitos e as rotas de recolha para três tipos de resíduos de embalagens vidro, papel/cartão e plástico/metal. A empresa em estudo, a Valnor, define as áreas de recolha (ou de influência) dos depósitos com base nos limites geográficos dos municípios, sendo todos os materiais recicláveis em cada local de recolha recolhidos a partir do mesmo depósito. A empresa deseja agora reestruturar as rotas efetuadas pelos veículos com o objetivo de reduzir a distância total percorrida e, consequentemente, diminuir os seus custos operacionais. De modo a melhor apoiar esta tomada de decisão da empresa, estudaram-se três cenários relativamente à configuração das áreas de recolha dos depósitos: (i) manter as áreas de recolha atuais e otimizar as rotas de recolha; (ii) reestruturar as áreas de recolha tornando-as distintas para cada material reciclável (cada depósito poderá ter três áreas de recolha diferentes); (iii) reestruturar as áreas de recolha por depósito (cada depósito terá apenas uma área de recolha comum aos três materiais). Com vista à resolução do problema, foi desenvolvido um método híbrido que combina procedimentos exatos com procedimentos heurísticos. A aplicação de técnicas de investigação operacional para a resolução deste caso permitiu encontrar soluções mais vantajosas face à situação atual implementada na empresa.

\section{PalavRAS-ChaVE}

Recolha de resíduos recicláveis, Áreas de influência, Roteamento, Planeamento. 


\section{Introdução}

A produção de resíduos tem aumentado significativamente nos últimos anos. Segundo dados do Instituto Nacional de Estatística (2010), a produção de resíduos em Portugal aumentou cerca de 20\% entre 2004 e 2009, tendo atingido o valor de 5.185 mil toneladas em 2009 (aproximadamente $511 \mathrm{~kg}$ por habitante). Com este crescimento torna-se evidente a necessidade de gerir os resíduos de uma forma eficaz, e de se tomarem medidas no sentido de incentivar a sua redução e a sua reutilização e reciclagem por fileiras. A reciclagem possibilita a valorização de matérias-primas que, de outra forma, teriam um ciclo de vida mais reduzido e, consequentemente, a preservação dos recursos naturais, economizando-se energia e reduzindo-se a quantidade de resíduos que são depositados em aterros sanitários.

Relativamente aos resíduos de embalagens - vidro, papel/cartão e plástico/metal - a União Europeia impôs metas de reciclagem aos estadosmembros, que os obrigou ao desenvolvimento de novos sistemas de recolha adequados às especificidades deste tipo de resíduos - o sistema de recolha seletiva. Em Portugal, o sistema integrado de gestão de resíduos de embalagens (SIGRE) é gerido pela Sociedade Ponto Verde, que conta com 32 sistemas aderentes para a recolha e triagem deste tipo de resíduos produzidos no território nacional.

Neste contexto, surge o caso em estudo da empresa responsável pela recolha e triagem dos resíduos produzidos em 19 municípios do norte Alentejo e Ribatejo, servindo cerca de 180 mil habitantes - a Valnor ${ }^{1}$. A sua área de intervenção não se esgota na recolha seletiva e triagem de resíduos de embalagens. Diversos tipos de resíduos são alvo de recolha, triagem, valorização e tratamento por parte da Valnor: resíduos sólidos urbanos indiferenciados, óleos alimentares usados, pneus usados, equipamentos elétricos e eletrónicos, veículos em fim de vida, resíduos de construção e demolição, resíduos volumosos, entre outros. O sistema de recolha seletiva de resíduos de embalagens é composto por 1275 vidrões, 1018 papelões e 1017 embalões, dispersos por 167 localidades. A empresa detém uma frota de

\footnotetext{
${ }^{1}$ Este trabalho foi realizado no início do ano 2011, com dados relativos ao ano 2010, quando a área de intervenção da Valnor incluía 19 municípios.
} 
veículos que se encontra dividida entre dois depósitos, sendo um deles a estação de triagem. A existência de mais do que um depósito implica a definição da área de influência dos depósitos, delimitando geograficamente a responsabilidade pela recolha dos contentores. Cada depósito é responsável por definir as rotas de recolha por material, uma vez que estes têm de ser recolhidos separadamente. Neste processo são considerados dois tipos de fluxos: o transporte primário dos resíduos recicláveis dos contentores de recolha para os depósitos, e o transporte secundário entre os depósitos e a estação de triagem.

Atualmente, a empresa em estudo define as áreas de influência dos depósitos com base nos limites geográficos dos municípios. Consequentemente, todos os materiais recicláveis em cada local são recolhidos a partir do mesmo depósito. A empresa deseja reestruturar estas áreas de influência com o objetivo de reduzir a distância total percorrida, diminuindo assim os seus custos operacionais. Complementarmente, a empresa pretende aferir o impacto de ter áreas de influência por material reciclável (onde a recolha dos diferentes materiais pode ser efetuada a partir de depósitos diferentes) em vez das atuais áreas definidas por depósito. O redimensionamento da frota de veículos e a determinação do número de motoristas estão também em análise.

Tendo em conta que se pretende definir as áreas de influência dos depósitos e as rotas de recolha para três tipos de produtos de modo a minimizar a distância total percorrida (incluindo o transporte primário e secundário), o problema apresentado pela empresa é modelado como um Multi-Product, Multi-Depot Vebicle Routing Problem (MP-MDVRP). Neste caso, a definição das rotas é considerado um problema de natureza tática, uma vez que as decisões tomadas serão mantidas durante um período de médio prazo dada a estabilidade existente nas taxas de enchimento dos contentores. Assim, pretende-se definir rotas estáticas (e não dinâmicas) não havendo, por isso, fortes condicionantes relativamente ao tempo computacional, uma vez que a solução encontrada será repetida ao longo do tempo e apenas revista por razões de sazonalidade e/ou aumento/diminuição significativo das quantidades depositadas nos contentores. Por este motivo, a abordagem seguida para a resolução do problema passou pela combinação de procedimentos exatos 
(mais morosos) com procedimentos heurísticos (mais ágeis), de forma a encontrar uma solução com boa qualidade num tempo computacional razoável para um nível de decisão tático.

Este capítulo está estruturado da seguinte forma. Na secção 2 será realizada uma breve revisão da literatura sobre problemas de rotas de veículos com múltiplos depósitos. Na secção 3 será descrito o problema $M P-M D V R P$ e detalhado o método híbrido desenvolvido para a resolução do mesmo. A aplicação do método ao caso real será apresentada na secção 4, onde se pormenorizará todo o processo de recolha dos dados necessários à aplicação em estudo. Finalmente, a discussão e considerações finais serão apresentadas na secção 5.

\section{Problemas de rotas de veículos com múltiplos depósitos}

O problema de rotas de veículos (VRP - Vebicle Routing Problem, na literatura inglesa) pode ser descrito como a definição de rotas ótimas de entrega ou de recolha a partir de um depósito, para um conjunto de cidades ou clientes dispersos geograficamente, tendo em conta um conjunto de restrições (Laporte, 1992). O problema de rotas de veículos com múltiplos depósitos (MDVRP - Multi-Depot Vebicle Routing Problem, na literatura inglesa) aparece como uma generalização do $V R P$ onde, para além da sequência de visita de cada veículo, é também necessário definir qual o depósito que serve cada ponto de entrega ou de recolha. Assim, o MDVRP estabelece simultaneamente as áreas de influência de cada depósito e as rotas de veículos associadas. Estas rotas são definidas de forma a: (1) cada rota começar e terminar no mesmo depósito; (2) cada cliente ser visitado apenas uma vez por um veículo; (3) a procura total de cada rota não exceder a capacidade máxima do veículo; (4) a duração total de cada rota, incluindo os tempos de deslocação e os tempos de serviço, não exceder o limite pré-definido. A solução ótima será aquela que minimiza o custo total, podendo este custo ser traduzido em unidades monetárias, tempo ou distância.

O MDVRP é geralmente definido num grafo $G=(V, A)$ constituído pelo conjunto de vértices $V=\{1, \ldots, n+w\}$ e pelo conjunto de arcos $A=\{(i, j): i, j \in V, i \neq j\}$. O conjunto de vértices $V$ está particionado em 
dois subconjuntos $V_{c}=\{1, \ldots, n\}$ e $V_{d}=\{n+1, \ldots, n+w\}$ representando, respetivamente, o conjunto de clientes e o conjunto de depósitos. O conjunto de rotas de veículos $K$ está particionado entre os vários depósitos, $K=K_{1} \cup \ldots \cup K_{i}$, onde $K_{i}$ representa o conjunto de rotas de veículos afetos ao depósito $i \in V_{d}$. Cada rota de veículo $k$ tem uma capacidade $Q$. Cada vértice $i$ tem uma procura $p_{i}$ e um tempo de serviço $t_{i}$. Ao conjunto $A$ está associada uma matriz distância $D=\left(d_{i j}\right)$.

Para a resolução do MDVRP foram desenvolvidos vários modelos, explorando abordagens exatas e aproximadas. Tendo em conta a natureza combinatória deste tipo de problema, os modelos propostos na literatura são predominantemente heurísticos. Existem, no entanto, alguns trabalhos que propõem abordagens exatas. Laporte et al. (1984), assim como Laporte et al. (1988) desenvolveram algoritmos exatos de branch and bound que só são aplicáveis a instâncias de pequena dimensão. Recentemente, Baldacci e Mingozzi (2009) desenvolveram um método exato para a resolução do problema de rotas com heterogeneidade nas capacidades dos veículos, que também é capaz de resolver, entre outros, o MDVRP. Relativamente aos métodos aproximados, várias abordagens têm sido desenvolvidas: (i) abordar o problema em duas fases, em que na primeira os clientes são afetos ao depósito de acordo com um determinado critério e na segunda fase, para cada depósito, é resolvido um VRP (Golden et al. (1977), Lim e Wang (2005)); (ii) abordar o problema de forma integrada, em que a afetação aos depósitos e a construção das rotas é realizada em simultâneo (Tillman e Cain (1972), Salhi e Sari (1997)); (iii) construção de uma solução inicial e aplicação de meta-heurísticas (Renaud et al. (1996), Pisinger e Ropke (2007), Ho et al. (2008)).

Existem algumas variantes do MDVRP estudadas na literatura. Crevier et al. (2007) estudaram o MDVRP com rotas entre depósitos (Multi-Depot Vebicle Routing Problem with Inter-Depot Routes), Hadjiconstantinou e Baldacci (1998) e Vidal et al. (2012) estudaram o MDVRP periódico (Multi-Depot Periodic Vebicle Routing Problem), Bettinelli et al. (2011) investigaram o MDVRP com janelas temporais de entrega e frota de veículos heterogénea (Multi-Depot Heterogeneous Vebicle Routing Problem with Time Windows). Parthanadee e Logendran (2006) consideram um problema de distribuição com múltiplos 
depósitos e produtos num contexto periódico (Multi-Product, Multi-Depot Periodic Distribution Problem). Neste problema, as encomendas colocadas pelos clientes contemplam diversos produtos, sendo necessário definir as rotas de distribuição ótimas para servir esses clientes a partir de vários depósitos. Os autores consideram o cenário do cliente ser abastecido por depósitos diferentes, se existir rotura de stock de algum produto no depósito que habitualmente o abastece. Portanto, no problema estudado por estes autores, os clientes podem ser visitados por diferentes depósitos para abastecimento dos múltiplos produtos encomendados. Assim, as áreas de influência dos depósitos podem ser definidas considerando cada produto individualmente, ou seja, resolvendo de forma independente um MDVRP para cada produto. No MP-MDVRP considerado neste trabalho, a definição das áreas de influência dos depósitos tem em conta os múltiplos produtos em simultâneo e obriga a que, em cada cliente, todos os produtos tenham de ser abastecidos (ou recolhidos) a partir do mesmo depósito.

\section{O Multi-Product, Multi-Depot Vebicle Routing Problem}

\subsection{Descrição do Problema}

O MDVRP considera que a procura do cliente $i\left(p_{i}\right)$ é de apenas um tipo de produto. O MP-MDVRP considera que a procura do cliente $i$ pode ser constituída por um conjunto de produtos (conjunto $M$ ), ou seja, $p_{\text {im }}$ representa a procura do cliente $i$ para o produto $m$. Combinando a multiplicidade de produtos com a multiplicidade de depósitos, duas situações podem ocorrer relativamente à definição das áreas de influência dos depósitos: a) todos os produtos em cada cliente são abastecidos (ou recolhidos) a partir do mesmo depósito - pelo que cada depósito tem uma área de influência comum a todos os produtos (áreas de influência por depósito); b) os produtos em cada cliente podem ser abastecidos (ou recolhidos) a partir de depósitos diferentes - pelo que cada depósito tem um número de áreas de influência correspondente ao número de produtos existentes (áreas de influência por produto). No primeiro caso estamos perante um $M P-M D V R P$ que consiste na definição das rotas ótimas de distribuição (ou recolha) a partir de múltiplos depósitos, impondo-se que cada cliente tenha todos os produtos abastecidos 
(ou recolhidos) pelo mesmo depósito. No segundo caso, estamos perante um MDVRP dado que o problema pode ser resolvido de forma independente para cada produto.

A formulação matemática para o $M P-M D V R P$ considera as seguintes variáveis de decisão:

- $\quad x_{i j m k}$, variável binária que representa a sequência de visita:

$=1$, se o nó $j$ é visitado imediatamente após o nó $i$, para recolher o material $m$, pela rota $k$; 0 , caso contrário;

- $\quad y_{i j m k}$, variável contínua que representa a carga de material $m$, na rota $k$, quando o arco $(i, j)$ é atravessado;

- $\quad z_{\text {imk }}$, variável binária que afeta os locais de recolha às rotas:

$=1$, se o local de recolha $i$, com o material $m$, é visitado pela rota $k$;

0 , caso contrário.

O MP-MDVRP consiste na definição da sequência de visita que minimiza a distância total a percorrer garantindo: (i) que cada local de recolha $i$ com o material $m$ é visitado uma só vez, (ii) que cada rota $k$ começa e termina no seu depósito de origem, (iii) que a capacidade do veículo para transportar o material $m$ não é ultrapassada, (iv) que a duração da rota respeita o tempo disponível de um dia de trabalho, $(v)$ a continuidade da rota, ou seja, quando a rota $k$ visita um local de recolha, tem de sair do mesmo, (vi) que a rota $k$ não pode recolher mais do que um tipo de material, (vii) que todos os materiais em cada local $i$ são recolhidos a partir do mesmo depósito.

A formulação desenvolvida considera $2 \times|V| \times|V| \times|M| \times|K|+|V| \times|M| \times|K|$ variáveis de decisão, conseguindo-se apenas resolver problemas de pequena dimensão. Para problemas de média e grande dimensão foi desenvolvido um método de resolução híbrido, que será detalhado na secção seguinte.

\subsection{Método de resolução híbrido}

Para a resolução do problema em causa, optou-se por uma abordagem híbrida, ou seja, uma abordagem que combina formulações matemáticas com um procedimento heurístico de decomposição. Neste caso, o problema original (MP-MDVRP) é decomposto em quatro sub-problemas, sendo estes modelados com formulações lineares inteiras mistas (ver Figura 1). 


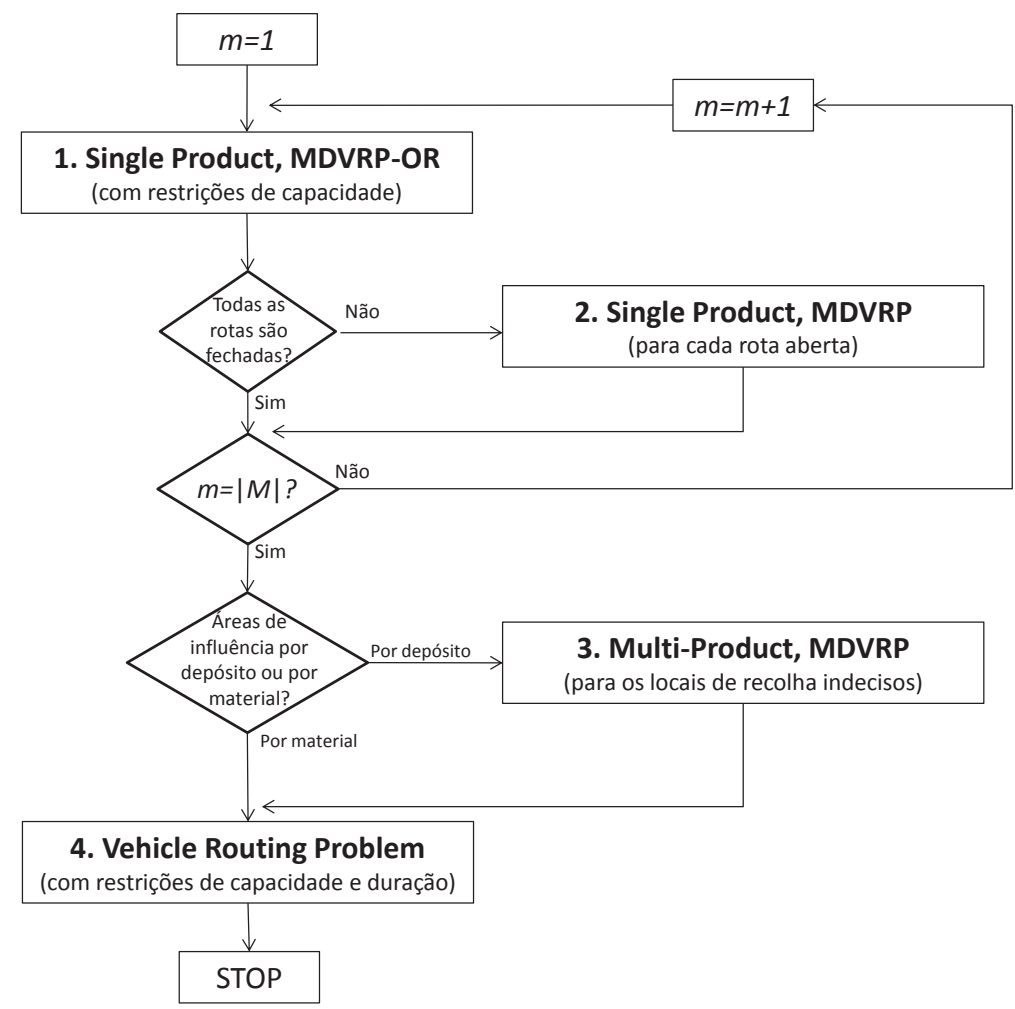

Figura 1: Fluxograma do método híbrido

Como referido anteriormente, pretende-se avaliar duas situações relativas à definição das áreas de influência: $a$ ) áreas de influência por depósito e b) áreas de influência por material. O método desenvolvido está preparado para lidar com ambas as situações. Se o objetivo for definir áreas de influência por depósito, os quatro módulos são executados; se o objetivo for definir áreas de influência por material, então o módulo 3 não será executado (ver Figura 1).

No método de decomposição representado na Figura 1, o primeiro módulo contempla uma simplificação do problema original (MP-MDVRP) para o problema Single-Product, Multi-Depot Vebicle Routing Problem with Open Routes (Single-Product, MDVRP-OR). No problema original existem múltiplos produtos e todas as rotas têm de começar e terminar no mesmo depósito (rotas fechadas); no problema do módulo 1 considera-se apenas um produto de cada 
vez e são permitidas rotas abertas entre depósitos (rotas que não começam e terminam no mesmo depósito). Este módulo é executado tantas vezes quanto o número de produtos a recolher $(|M|)$. Como solução obtêm-se rotas que começam e terminam no mesmo depósito (rotas fechadas) e rotas que não começam e terminam no mesmo depósito (rotas abertas). Dado que no problema original apenas são admitidas rotas fechadas, se existirem rotas abertas na solução final, seguir-se-á a execução do segundo módulo.

Os locais de recolha que pertencem às rotas abertas serão o input deste segundo módulo, onde o problema $M D V R P$, formulado em programação linear inteira mista (PLIM), é resolvido. No MDVRP são definidas apenas rotas fechadas, pelo que os locais de recolha que pertencem a rotas abertas serão naturalmente afetos a um único depósito.

Se o módulo 1 não gerar rotas abertas ou terminada a execução do módulo 2, coloca-se a questão sobre o critério para a definição das áreas de influência. Se o objetivo for a definição de áreas de influência por material, o quarto módulo é executado onde, para cada depósito e para cada material, é resolvida uma formulação em PLIM para o VRP. Se o objetivo for a definição de áreas de influência por depósito, é necessário analisar os resultados obtidos nos módulos anteriores (módulos 1 e 2) considerando todos os materiais em simultâneo e verificar se, para cada local de recolha, todos os materiais são recolhidos a partir do mesmo depósito. Quando existem divergências na afetação entre os materiais, esses locais são designados de "indecisos" e o módulo 3 é executado antes do módulo 4 de forma a decidir a afetação final desses locais, considerando todos os materiais em simultâneo.

Os quatro módulos envolvem o desenvolvimento de formulações matemáticas que tiveram em conta as características do problema em estudo. O detalhe de cada módulo é descrito de seguida.

\section{Módulo 1}

A formulação proposta para o Single-Product, MDVRP-OR é baseada na two-commodity flow formulation proposta por Baldacci et al. (2004) para o Capacitated Vehicle Routing Problem (CVRP). Todas as rotas começam num depósito real e terminam num depósito réplica. 
Cada rota é definida por dois fluxos: um fluxo com origem no depósito real e destino no depósito réplica, definido pela variável $y_{i j}$ (que representa a carga no veículo e que irá aumentando ao longo da rota); o outro fluxo, representando o caminho inverso, começa no depósito réplica e termina no depósito real; este é definido pela variável $y_{j i}$ (que representa o espaço vazio no veículo e que irá diminuindo ao longo da rota). A Figura 2 ilustra os dois caminhos que formam uma rota.

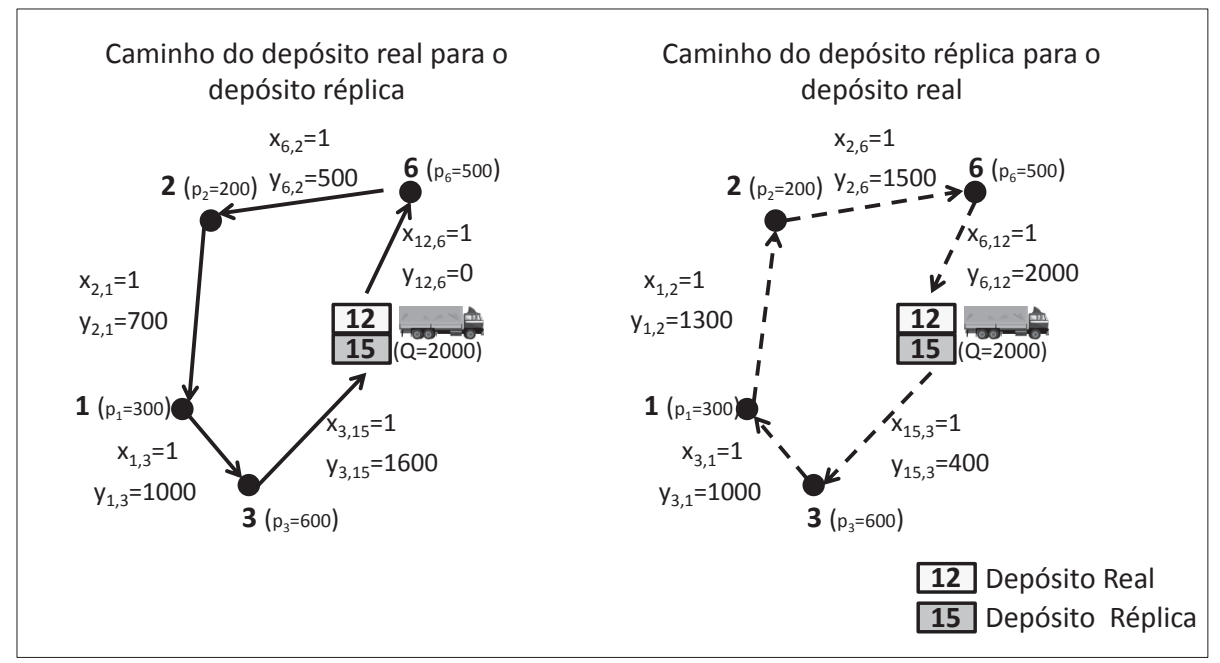

Figura 2: Ilustração dos dois caminhos que formam uma rota

No Single-Product, MDVRP-OR as rotas têm de começar e terminar num depósito mas não necessariamente no mesmo, como acontece no MDVRP. Os índices, conjuntos, parâmetros e variáveis de decisão da formulação proposta para o Single-Product, $M D V R P-O R$ são apresentados de seguida:

Índices

$i, j \quad$ Indice dos nós

Conjuntos

$\bar{V} \quad$ Conjunto dos nós $\bar{V}=\{1, \ldots, n+2 w+s\}, \bar{V}=V_{c} \cup V_{d} \cup V_{f} \cup V_{s}$

$V_{c} \quad$ Conjunto dos locais de recolha $V_{c}=\{1, \ldots, n\}$

$V_{d} \quad$ Conjunto dos depósitos reais $V_{d}=\{n+1, \ldots, n+w\}$

$V_{f} \quad$ Conjunto dos depósitos réplica $V_{f}=\{n+w+1, \ldots, n+2 w\}$

$V_{s} \quad$ Conjunto das estações de triagem $V_{s}=\{n+2 w+1, \ldots, n+2 w+s\}$ 


\section{Parâmetros}

$d_{i j} \quad$ Distância entre o nó i e o nó j (em metros)

$p_{i} \quad$ Quantidade a recolher no local de recolha i $(\mathrm{em} \mathrm{kg})$

$c_{i} \quad$ Número de contentores no local de recolha $i$

fr Frequência de recolha no horizonte temporal

Q Capacidade do veículo para o transporte primário (em $\mathrm{kg}$ )

QT Capacidade do veículo para o transporte secundário (em $\mathrm{kg}$ )

E Distância média entre dois contentores dentro de um local de recolha (em metros)

$R \quad$ Número máximo de rotas

Variáveis de Decisão

$x_{i j} \quad$ Variável binária que representa a sequência de visita ( $x_{i j}=1$ se o nó jé visitado após o nó $i ; x_{i j}=0$ caso contrário)

$y_{i j} \quad$ Variável contínua que representa a carga no veículo quando atravessa o arco $(i, j)$. A variável $y_{j i}$ representa o espaço vazio no veículo quando o $\operatorname{arco}(i, j)$ é atravessado.

Modelo Matemático

$$
\begin{aligned}
& \operatorname{Min} H=\frac{1}{2} \sum_{i \in V} \sum_{\substack{j \in V \\
j \neq i}} x_{i j} d_{i j} f r+\sum_{i \in V_{c}} c_{i} E f r+2 \sum_{i \in V_{f}} \sum_{j \in V_{c}} \sum_{h \in V_{s}} \frac{y_{j i} f r}{Q T} d_{h i} \\
& \sum_{\substack{j \in V V_{s} \\
j \neq i}}\left(y_{i j}-y_{j i}\right)=2 p_{i}, \quad \forall i \in V_{c} \\
& \sum_{\substack{i \in V_{c} \\
j \in V_{f}}} y_{i j}=\sum_{i \in V_{c}} p_{i} \\
& \sum_{\substack{j \in V_{f} \\
\sum_{i \in V_{c}}}} y_{j i} \leq R Q-\sum_{i \in V_{c}} p_{i} \\
& \sum_{\substack{i \in V_{c} \\
j \in V_{d}}} y_{i j} \leq R Q \quad \forall j \in V_{c}: p_{j} \neq 0 \\
& \sum_{i \in V V_{s}} x_{i j}=2, \quad \forall i \neq j \\
& y_{i j}+y_{j i}=Q x_{i j} \quad \forall i, j \in \bar{V} \backslash V_{s}, i \neq j
\end{aligned}
$$




$$
\begin{aligned}
& x_{i j} \in\{0,1\} \quad \forall i, j \in \bar{V} \backslash V_{s} \\
& y_{i j} \geq 0, y_{j i} \geq 0 \quad \forall i, j \in \bar{V} \backslash V_{s}
\end{aligned}
$$

A função objetivo, equação (1), modela a minimização da distância total percorrida, que inclui a distância percorrida no transporte primário (primeira e segunda parcelas) e a distância percorrida no transporte secundário (terceira parcela).

O transporte primário considera a distância entre os locais de recolha e os depósitos sendo, como referido anteriormente, as rotas são definidas por dois caminhos. Isto significa que cada arco é contado duas vezes na solução, duplicando a distância real percorrida. Assim, esta parcela tem de ser dividida por dois para eliminar o valor do segundo caminho. A segunda parcela do transporte primário está relacionada com a distância a percorrer dentro de cada local para recolher todos os contentores existentes. Este valor não depende de nenhuma variável de decisão pelo que é constante, mas foi incluído na função objetivo para contabilizar a distância total percorrida. De referir que esta segunda parcela contempla o número total de contentores existentes em cada local de recolha $\left(c_{i}\right)$ e não $\left(c_{i}-1\right)$, de modo a considerar a distância a percorrer desde a entrada na localidade (local de recolha) até ao primeiro contentor ou desde o último contentor até à saída da localidade.

O transporte secundário consiste em deslocações de ida e volta entre os depósitos e as estações de triagem, razão pela qual o terceiro termo encontrase multiplicado por dois.

A equação (2) garante que, para cada local de recolha, a diferença entre o fluxo de saída e o fluxo de entrada é igual a duas vezes a quantidade a ser recolhida nesse local (devido aos dois caminhos que definem as rotas).

As restrições (3), (4) e (5) modelam os fluxos de entrada e saída dos depósitos reais e dos depósitos réplica.

A equação (6) garante que, em qualquer solução admissível, cada local de recolha tem dois arcos incidentes.

A equação (7) garante que a capacidade de cada rota não é ultrapassada.

As restrições (8) e (9) definem os domínios das variáveis. 


\section{Módulo 2}

O módulo 2 é executado apenas se o módulo 1 produzir uma solução que contenha rotas abertas. O objetivo deste módulo é afetar a um único depósito os locais de recolha que pertencem a este tipo de rotas, utilizando-se, para tal, uma formulação em PLIM para o MDVRP. Dado que o MDVRP apenas admite soluções com rotas fechadas, os nós são naturalmente afetos a um único depósito. Neste módulo apenas se consideram os locais de recolha que pertencem a cada rota aberta e o módulo é executado considerando cada rota separadamente. Como resultado, estes locais de recolha podem ser todos afetos a um só depósito ou divididos pelos vários depósitos existentes.

A formulação em PLIM para o $M D V R P$ considera um conjunto de rotas de veículos $K$, a que corresponde o índice $k$, e a variável binária $z_{i k}$ que afeta a rota $k$ ao local de recolha $i$. As variáveis $x_{i j}$ e $y_{i j}$ da formulação do módulo 1 são redefinidas de modo a contemplarem a rota a que estão afetas - $x_{i j k}$ e $y_{i j k}$. A variável binária $x_{i j k}$ toma o valor 1 se o nó $j$ é visitado imediatamente após o nó $i$, pela rota $k$ e a variável contínua $y_{i j k}$ representa a carga transportada na rota $k$ quando o arco $(i, j)$ é atravessado. Para que exista sequência de visita entre o nó $i$ e $j\left(x_{i j k}=1\right)$ e o respetivo fluxo de carga $\left(y_{i j k}\right)$, os nós $i$ e $j$ têm de estar afetos à mesma rota $k\left(z_{i k}=1 \wedge z_{j k}=1\right)$. As restrições (1) a (9) são reescritas de forma a contemplarem estas alterações e são adicionadas restrições que garantem que as rotas começam no depósito real e terminam no depósito réplica correspondente.

\section{Módulo 3}

O módulo 3 é executado apenas se se pretender definir áreas de influência por depósito. Neste caso, em cada local de recolha, todos os materiais recicláveis têm de ser recolhidos pelo mesmo depósito. Assim, os resultados obtidos nos módulos anteriores para os diferentes materiais recicláveis são agora analisados em simultâneo, podendo existir situações em que o mesmo local é visitado por veículos provenientes de depósitos diferentes, consoante o material a recolher. Considerando, por exemplo, três materiais recicláveis $\left(m_{1}\right.$, $m_{2}, m_{3}$ ), o local de recolha $i$ pode ter o material $m_{1}$ recolhido pelo depósito $d_{1}$, mas ser o depósito $d_{2}$ a recolher o material $m_{2}$ e o depósito $d_{3}$ a recolher 
o material $m_{3}$. Deste modo, três situações podem acontecer: (i) não existir acordo entre os materiais; (ii) existir acordo entre dois materiais; (iii) existir acordo entre todos os materiais. Os locais de recolha que se encontram nos casos (i) e (ii) são designados de "indecisos". Neste módulo 3 é resolvida a formulação em PLIM para o MP-MDVRP descrita na secção 3.1 apenas considerando os locais de recolha "indecisos". Esta redução da dimensão do problema (tomando apenas o conjunto dos locais de recolha indecisos, em vez do conjunto original - levando a redução da cardinalidade dos conjuntos $V$ e $K$ ) permite a utilização da formulação original. Como mencionado, esta formulação considera um conjunto de materiais recicláveis $M$, a que corresponde o índice $m$, pelo que as variáveis de decisão passam a ser $x_{i j m k}$, $y_{i j m k} \mathrm{e} z_{\text {imk }}$. Consequentemente, as restrições são reescritas de modo a contemplarem o conjunto $M$, sendo adicionada uma restrição que garante que, em cada local de recolha, todos os materiais são recolhidos pelo mesmo depósito.

\section{Módulo 4}

Uma vez que as áreas de influência já estão definidas, o módulo 4 irá definir as rotas finais para cada depósito e para cada material. Neste caso serão consideradas restrições de duração das rotas, o que até agora não foi tido em conta. Esta última formulação baseia-se na formulação apresentada para o módulo 1, embora exista apenas um depósito real e, consequentemente, um depósito réplica (em vez de múltiplos). Para modelar a duração das rotas foram definidas duas novas variáveis de decisão: $a_{i j}$ que representa o tempo de chegada ao nó $j$ com origem no nó $i$ e $e_{i j}$ que representa o tempo de saída do nó $i$ com destino ao nó $j$. Foram também considerados sete novos parâmetros:

$t_{i}$

Tempo necessário para recolher o material no local de recolha i (em minutos) $t_{i}=c_{i}\left(U+\frac{E}{v w}\right)$

$b_{i j} \quad$ Tempo de deslocação entre o nó $i$ e o nó $j$ (em minutos) $b_{i j}=\frac{d_{i j}}{v b}$

$v b \quad$ Velocidade entre locais de recolha (em metros por minuto) 
vw Velocidade dentro dos locais de recolha (em metros por minuto)

U Duração da recolha de um contentor (em minutos)

$L \quad$ Tempo de descarga do veículo no fim de uma rota (em minutos)

$T \quad$ Duração máxima de um dia de trabalho por motorista (em minutos)

Para além das situações anteriormente referidas, esta formulação modela também as seguintes situações: (i) a duração de uma rota não pode ultrapassar $T$-L minutos; (ii) o tempo de chegada ao nó $j$ corresponde ao tempo de saída do nó $i$ mais o tempo de deslocação entre $i$ e $j$; (iii) o tempo de saída do nó $i$ corresponde ao tempo de chegada ao nó $i$ mais o tempo necessário para proceder à recolha neste nó.

As formulações matemáticas desenvolvidas para cada um dos quatro módulos foram escritas em Gams 23.7 e resolvidas de forma independente através do método de branch-and-cut disponibilizado no ILOG CPLEX 12.3 (ILOG-CPLEX, 2011) em versão paralela, num Two Intel Xeon X5680 @ 3.33GHz, com 24 GB de RAM, com 6 núcleos em cada processador.

\section{Caso de estudo - Valnor}

A Valnor é responsável pela recolha seletiva de três tipos de resíduos de embalagens (vidro, papel/cartão, plástico/metal) em 19 municípios do norte Alentejo e Ribatejo. Os 3.310 contentores (1.275 vidrões, 1.018 papelões e 1.017 embalões) que compõem o seu sistema de deposição são recolhidos a partir de dois depósitos situados nos municípios de Avis e Abrantes. Toda a gestão das operações da Valnor baseia-se numa lógica municipal, ou seja, existe um circuito por concelho, exceto nos concelhos mais populosos (Ponte de Sôr, Portalegre e Elvas) onde existem dois circuitos, e no concelho de Abrantes onde existem 3 circuitos, totalizando 24 circuitos. Por outro lado, também as áreas de intervenção de cada depósito são definidas com base nos limites dos municípios (ver Figura 3).

Para a recolha de vidro, os 24 circuitos foram repetidos anualmente num total de 373 circuitos por ano (considerando o período de Novembro 2009 a Outubro 2010). Em média, cada circuito foi percorrido 15,54 vezes, dando origem a um intervalo médio entre recolhas de 3,35 semanas (ver Tabela 1). Para a recolha de papel, a repetição dos 24 circuitos totalizou 954 circuitos 
anuais. Cada circuito foi executado, em média, 39,75 vezes no período em análise, dando origem a um intervalo médio entre recolhas de 1,31 semanas. Finalmente, para o plástico/metal, em média, cada um dos 24 circuitos foi repetido 40,7 vezes num ano (num total de 977 circuitos), o que perfaz um intervalo médio entre recolhas de 1,28 semanas.

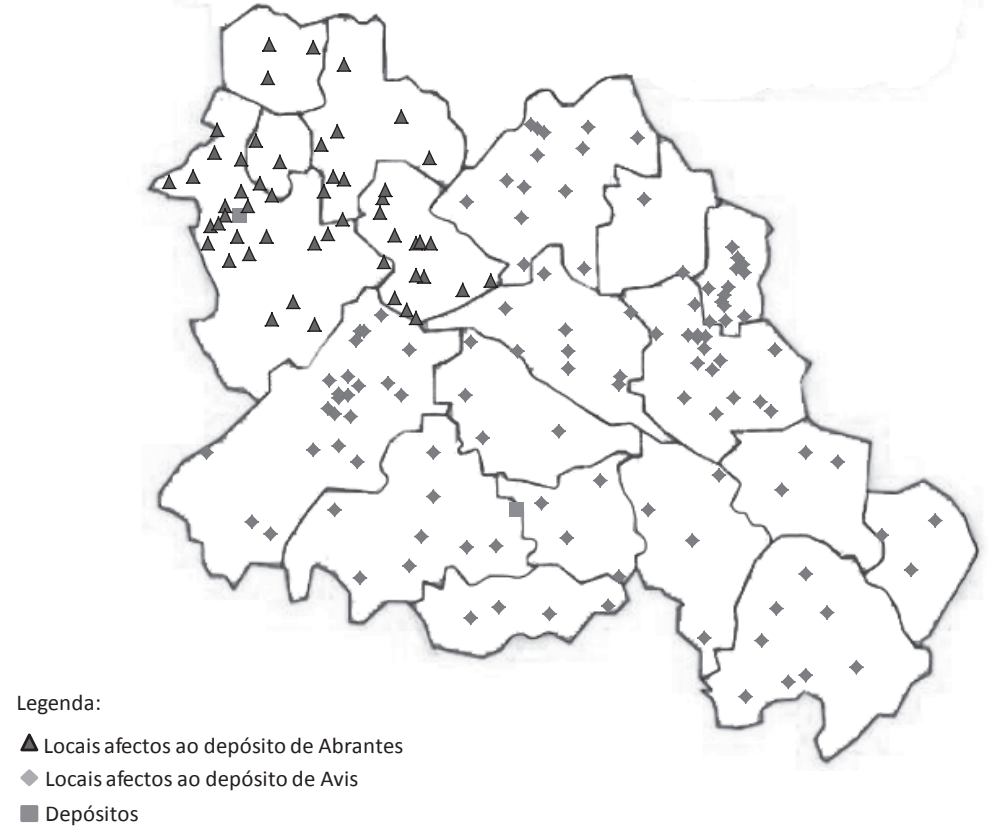

Figura 3: Áreas de influência atuais

Tabela 1: Intervalo entre recolhas por tipo de material, no período de Novembro 2009 a Outubro de 2010 (em semanas)

\begin{tabular}{lccc}
\hline & Vidro & Papel & Plástico/Metal \\
\hline Máximo & 5,84 & 2,9 & 3,06 \\
Média & 3,35 & 1,31 & 1,28 \\
Moda & 4 & 1,6 & 1,7 \\
Mínimo & 1,18 & 0,5 & 2,04 \\
\hline
\end{tabular}

Verificou-se também que a taxa média de enchimento dos contentores no momento da recolha foi de $21 \%$ para o vidro e de $23 \%$ para o papel e plástico/metal (ver Tabela 2). Apenas no papel se verificou uma taxa máxima de enchimento de $100 \%$. 
Tabela 2: Peso recolhido por contentor e respetiva taxa de enchimento

\begin{tabular}{|c|c|c|c|c|c|c|}
\hline & \multicolumn{2}{|c|}{ Vidro } & \multicolumn{2}{|c|}{ Papel } & \multicolumn{2}{|c|}{ Plástico/Metal } \\
\hline & Peso (kg) & Tx.Enchim. & Peso $(\mathrm{kg})$ & Tx.Enchim. & Peso $(\mathrm{kg})$ & Tx.Enchim. \\
\hline Máximo & 464 & $77 \%$ & 200 & $100 \%$ & 68 & $57 \%$ \\
\hline Média & 127,96 & $21 \%$ & 46,71 & $23 \%$ & 28 & $23 \%$ \\
\hline Mínimo & 37,77 & $6 \%$ & 8,75 & $4 \%$ & 1 & $1 \%$ \\
\hline
\end{tabular}

A Valnor pretende agora reestruturar as suas áreas de influência dos depósitos e redefinir os circuitos de recolha de modo a diminuir a distância total percorrida, reduzindo assim os seus custos operacionais. Para cumprir este objetivo, o método apresentado na secção 3 foi aplicado ao caso Valnor. Não existindo nenhuma imposição legal ou contratual relativa à periodicidade dos circuitos, e tendo em conta a reduzida taxa média de enchimento atual, a Valnor pretende também redefinir o intervalo entre recolhas, garantindo que a referida taxa de enchimento não ultrapasse 80\%. Sendo a periodicidade das rotas um parâmetro do modelo, esta questão será detalhada na secção seguinte, assim como todo o processo de recolha de dados necessários ao modelo.

\subsection{Recolha e tratamento de dados}

Os dados necessários foram obtidos através de entrevistas ao gestor de operações e pela análise da base de dados dos circuitos realizados. A Valnor facultou a informação relativa aos circuitos efetuados durante Novembro de 2009 a Outubro de 2010. Para cada circuito existe informação sobre a data em que o mesmo ocorreu, qual o veículo utilizado, o tipo de resíduo que foi recolhido, o número de contentores recolhidos, o número de quilómetros percorridos, a duração do circuito e o peso recolhido. Neste período foram percorridos cerca de $277.300^{2} \mathrm{~km}$, congregando tanto o transporte primário como o secundário.

Os valores e a forma como se estimaram os vários parâmetros do modelo são apresentados de seguida.

\footnotetext{
${ }^{2}$ Por questões de confidencialidade, as distâncias apresentadas ao longo do capítulo não são as reais (foi aplicado um coeficiente a todas as distâncias).
} 


\subsubsection{Locais de recolha}

Os 3.310 contentores estão localizados em 167 localidades diferentes. Assim, um local de recolha agrega um ou mais contentores, de um ou mais materiais recicláveis. Por exemplo, a localidade "Vila de Rei" é um local de recolha com 12 contentores para a deposição de papel, 12 contentores para o plástico/metal e 16 contentores para o vidro. Assim, para determinar a distância percorrida e o tempo despendido dentro de cada localidade/local de recolha considerou-se a distância média entre os contentores, a velocidade média dentro das localidades e o tempo médio de recolha por contentor. Realce-se também o facto de nem todos os locais de recolha terem os três materiais para serem recolhidos. A título de exemplo, o local de recolha "Monte do Duque", no concelho de Nisa, tem um contentor para o papel e um contentor para o vidro, não existindo contentores para a recolha do plástico/metal.

Comparando a quantidade a recolher em cada local e a capacidade máxima dos veículos para o transporte primário, observaram-se algumas situações em que a quantidade a recolher excede a capacidade do veículo. Nestes casos, os locais de recolha foram replicados o número de vezes necessário para respeitar a capacidade máxima dos veículos. A título de exemplo, o local de recolha "Ponte de Sôr" tem 49 contentores para papel e um peso total a recolher de $3.284 \mathrm{~kg}$ em cada visita. Sendo a capacidade do veículo para a recolha do papel de $2.000 \mathrm{~kg}$, este local de recolha foi replicado, repartindo-se o número de contentores e peso a recolher por dois locais: "Ponte de Sôr-1" com 29 contentores (correspondendo um peso de $1.944 \mathrm{~kg}$ ) e "Ponte de Sôr-2" com os restantes 20 contentores (com um peso de $1.340 \mathrm{~kg}$ ). Considerando a recolha do plástico/metal, "Ponte de Sôr" necessita também de 2 réplicas. Para além de "Ponte de Sôr", existem ainda outras 5 localidades onde foi necessário proceder de forma análoga: Abrantes (5 réplicas), Campo Maior (2 réplicas), Elvas (3 réplicas), Nisa (2 réplicas) e Portalegre (8 réplicas). Assim, em vez de 167 localidades consideraram-se 189 locais de recolha, o que corresponde a 178 locais com o material papel, 183 com o material plástico/metal e 174 com o material vidro. 


\subsubsection{Quantidade a recolher e periodicidade da recolha}

Para determinar a quantidade a recolher em cada local e a periodicidade da recolha calculou-se previamente a quantidade média diária depositada em cada contentor. Este cálculo baseou-se no intervalo de tempo entre duas realizações consecutivas do mesmo circuito, assim como na quantidade média depositada em cada contentor (ver Figura 4).

\begin{tabular}{|c|c|c|c|c|c|c|c|c|}
\hline Data & Circuito & Material & No Contentores & $\begin{array}{c}\text { Peso } \\
\text { (kg) }\end{array}$ & $\begin{array}{c}\text { Peso/Contentor } \\
\text { (kg) }\end{array}$ & $\begin{array}{c}\text { Intervalo } \\
\text { Tempo (dias) }\end{array}$ & $\begin{array}{c}\text { Peso/Contentor/Dia } \\
\text { (kg) }\end{array}$ \\
\hline $27 / 10 / 2010$ & 2 & Vidro & 58 & 4760 & 82,07 & 32 & 2,56 & \\
\hline $25 / 09 / 2010$ & 2 & Vidro & 59 & 5740 & 97,29 & 28 & 3,47 \\
\hline $28 / 08 / 2010$ & 2 & Vidro & 58 & 6380 & 110 & 29 & 3,79 & $\ldots$ \\
\hline $30 / 07 / 2010$ & 2 & Vidro & 57 & 5860 & 102,81 & - & $\ldots$ & $\ldots$ \\
\hline$\ldots$ & $\ldots$ & $\ldots$ & $\ldots$ & $\ldots$ & $\ldots$ & $\ldots$ & $\ldots$ \\
\hline
\end{tabular}

Figura 4: Exemplo do cálculo do peso médio por contentor por dia

De referir que para o cálculo da quantidade média diária depositada em cada contentor foram retirados alguns outliers detetados. A título exemplificativo apresenta-se na Figura 5 o caso do circuito do concelho do "Crato" para recolha de vidro. O outlier identificado corresponde a um aumento da deposição do material vidro, consequência da realização do Festival do Crato entre os dias 25 a 28 de Agosto de 2010. Assim, a quantidade recolhida antes do início do festival encontra-se num nível normal (dia 24 de Agosto de 2010), tendo a quantidade recolhida após o festival (dia 30 de Agosto de 2010) apresentado um valor extraordinário justificado pela realização do mesmo. Neste sentido, para o cálculo da quantidade média depositada diariamente por contentor retirou-se o valor do outlier identificado. Note-se que o valor médio com o outlier é de $5,18 \mathrm{~kg} /$ contentor/dia, sendo o valor médio sem outlier de $2,57 \mathrm{~kg} /$ contentor/dia.

Este procedimento para o cálculo do peso por contentor por dia assume que todos os contentores visitados em cada circuito apresentam a mesma deposição média diária. A quantidade a recolher em cada local de recolha/localidade irá depender do número de contentores existentes que, por sua vez, dependerá da população existente em cada localidade. Este cálculo da 
quantidade média depositada por dia em cada contentor é um passo intermédio para o cálculo da periodicidade da recolha.

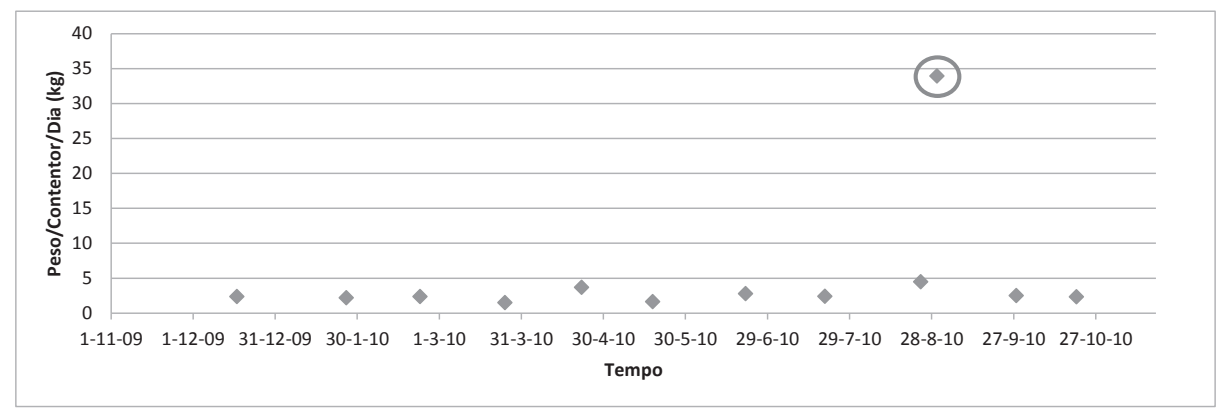

Figura 5: Peso por contentor por dia no circuito Crato para a recolha de vidro durante um ano

O intervalo de tempo entre recolhas para cada local depende da taxa de enchimento dos contentores que, por sua vez, depende da quantidade média depositada por dia, calculada anteriormente. O maior intervalo de tempo ditará o período de planeamento a considerar. Foi, no entanto, imposto um máximo de 6 semanas ( 1 semana $=7$ dias) o que corresponde ao intervalo máximo entre recolhas praticado atualmente pela Valnor. Desta forma, e assumindo um intervalo mínimo entre recolhas $(t)$ de 1 semana, aplicou-se o procedimento apresentado na Figura 6 de modo a determinar qual o padrão de recolha a efetuar para que nenhum contentor ultrapasse uma taxa de enchimento de 80\%.

O modelo desenvolvido exige que o intervalo de tempo entre recolhas por tipo de resíduo seja igual em todos os locais de recolha. Pela aplicação da metodologia apresentada obtiveram-se intervalos entre recolhas diferentes em vários locais de recolha com o mesmo tipo de resíduo. Para cumprir este requisito, a frequência a implementar para cada tipo de material corresponderá à frequência que permite que a taxa de enchimento de todos os contentores não ultrapasse os $80 \%$. Assim, para o material papel o intervalo entre recolhas determinado é de $t=2$ (14 dias), para o plástico/metal é de $t=3$ (21 dias) e para o vidro de $t=6$ ( 42 dias). Isto significa que no horizonte temporal de 6 semanas (intervalo máximo encontrado), a frequência de recolha de vidro é de 1 vez, a frequência de recolha do papel é de 3 vezes e, para o plástico/metal, esta frequência é de 2 vezes. 


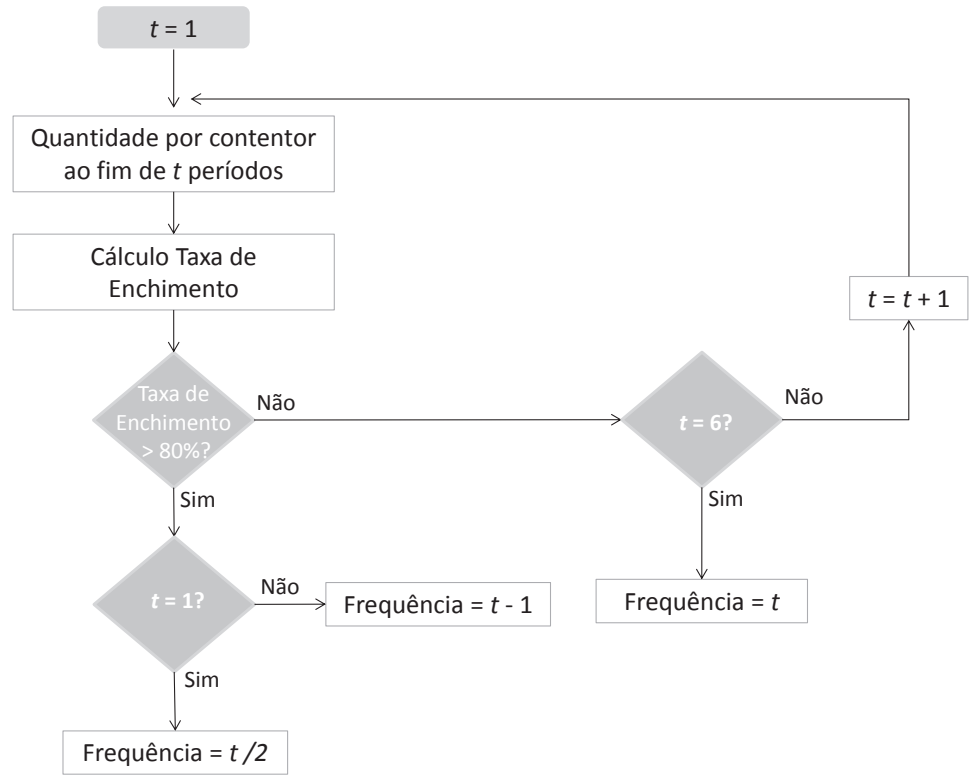

Figura 6: Procedimento para cálculo do intervalo de tempo entre recolhas

A quantidade diária por contentor multiplicada pelo intervalo entre recolhas de cada tipo de material indica o valor a recolher em cada contentor em cada visita. O peso a recolher em cada local resulta da agregação de todos os contentores que compõem esse local de recolha.

\subsubsection{Capacidade de recolha}

Devido à diferente densidade dos materiais, a capacidade dos veículos difere consoante o material a recolher. A capacidade máxima dos veículos $(Q)$ é de $2.000 \mathrm{~kg}$ para a recolha do papel, para o plástico/metal é de $1.000 \mathrm{~kg}$ e para o vidro é de $8.500 \mathrm{~kg}$. Para o transporte secundário são utilizados veículos de maior dimensão e, consequentemente, a capacidade de transporte é mais elevada ( $Q T$ ). Assim, para o transporte secundário de papel a capacidade máxima a considerar é de $5.000 \mathrm{~kg}$, para o plástico/metal é de $3.000 \mathrm{~kg}$ e para o vidro é de $12.000 \mathrm{~kg}$. A frota de veículos, quer para o transporte primário, quer para o secundário, é homogénea. 


\subsubsection{Tempo}

A duração máxima de uma rota é de 7 horas $(T=420$ minutos), onde se inclui o tempo de descarga do veículo quando este regressa ao depósito ( $L=$ 10 minutos). Esta duração máxima corresponde a um dia de trabalho para os motoristas. No entanto, o tempo disponível para a realização dos circuitos de recolha é de 63 horas por semana dado que em 4 dos 5 dias da semana realizam-se dois turnos $(14 \mathrm{~h} \times 4$ dias $+7 \mathrm{~h} \times 1$ dia). Isto significa que cada veículo pode operar um total de 378 horas no horizonte temporal de 6 semanas.

Para determinar o tempo de recolha dos contentores e a velocidade dos veículos dentro das localidades foi efetuado um modelo de regressão linear múltipla, em que a duração do percurso é explicada através do número de contentores recolhidos e da distância percorrida. No entanto, o coeficiente de correlação obtido não revelou um resultado satisfatório $\left(R^{2}=0,34\right)$, pelo que os parâmetros estimados pelo modelo de regressão não foram utilizados. Com base na experiência do gestor de operações da Valnor foram definidos os seguintes valores médios:

- Duração da recolha de um contentor $(U): 5$ minutos,

- Velocidade dentro das localidades $(v w): 10 \mathrm{~km} / \mathrm{hora}$.

Para a velocidade entre localidades $(v b)$ foi considerado um valor de 60 $\mathrm{km} /$ hora.

\subsubsection{Distâncias}

Existem dois tipos de distâncias a considerar. A distância a percorrer dentro de cada local de recolha e a distância a percorrer entre locais de recolha. A primeira corresponde ao número de contentores existentes em cada local multiplicado pela distância média entre dois contentores $(E)$. O valor apurado para $E$ foi de 500 metros, correspondendo à média de todas as distâncias entre contentores nas 167 localidades. A distância a percorrer entre locais de recolha e depósitos $\left(d_{i j}\right)$ foi obtida através de uma ferramenta de georreferenciação com base na rede viária disponível no Sistema de Informação Geográfica "ArcGis Online" (ArcGis, 2011). 


\subsection{Resultados obtidos}

De modo a apoiar a decisão por parte da empresa Valnor foram estudados três cenários relativamente à configuração das áreas de influência dos depósitos: (1) manter as áreas de influência atuais e otimizar as rotas de recolha; (2) reestruturar as áreas de influência por material reciclável (cada depósito poderá ter três áreas de influência distintas); (3) reestruturar as áreas de influência por depósito (cada depósito terá apenas uma área de influência comum aos três materiais). De referir que, como se pretendeu também determinar qual o número mínimo de veículos necessários, o valor do parâmetro $R$, nos módulos 1 e 4 , e a cardinalidade do conjunto $K$, nos módulos 2 e 3, foram suficientemente elevados para não limitarem a solução.

\subsubsection{Cenário 1: manter as áreas de influência atuais}

As áreas de influência definidas pela Valnor respeitam os limites geográficos dos municípios. Assim, o depósito de Abrantes é responsável pelas localidades situadas nos concelhos de Abrantes, Sardoal, Vila de Rei, Mação e Gavião, totalizando 57 locais de recolha. O depósito e estação de triagem de Avis é responsável pelos restantes 14 municípios, totalizando 132 locais de recolha. Neste cenário, como são assumidas as áreas de influência da Valnor, apenas foi necessário executar o módulo 4 de modo a otimizar as rotas de recolha de cada depósito.

Os resultados obtidos indicam que a distância total a percorrer no horizonte temporal de 6 semanas é de $29.399 \mathrm{~km}$, dos quais $25.751 \mathrm{~km}$ (cerca de 88\%) correspondem ao transporte primário e $3.648 \mathrm{~km}$ (cerca de 12\%) ao secundário. O depósito de Abrantes é responsável por 36\% do total da distância percorrida, que inclui a totalidade do transporte secundário (ver Figura 7).

A título exemplificativo apresenta-se na Figura 8 a solução obtida para a recolha do material papel no depósito de Abrantes. Pode-se observar que foram definidas oito rotas, três das quais (\#2, \#7 e \#8) correspondem a rotas diretas à localidade de Abrantes dado o volume de material a recolher. Ao contrário das rotas atuais que se cingem aos limites dos concelhos, na solução proposta para este cenário vários concelhos são integrados numa mesma rota (por exemplo, a rota $\# 1$ passa por 5 municípios diferentes). Como o intervalo 
entre recolhas para o papel é de 2 semanas, as rotas definidas serão repetidas três vezes durante o horizonte temporal.

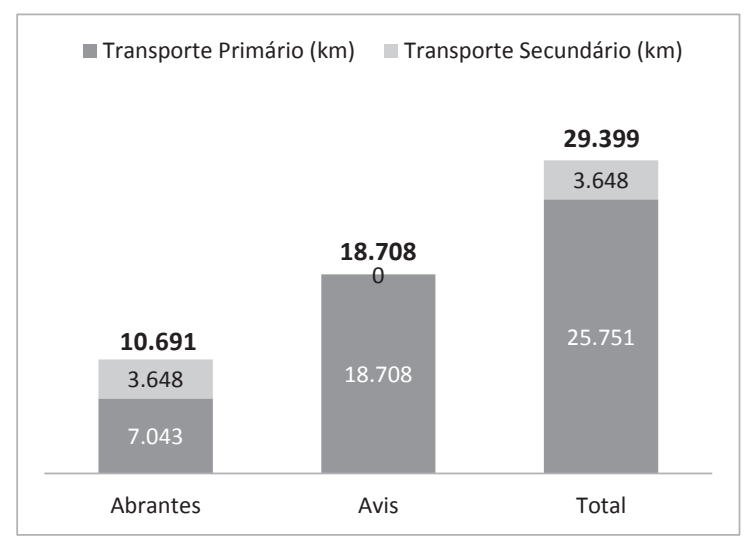

Figura 7: Distância total a percorrer por depósito no cenário 1

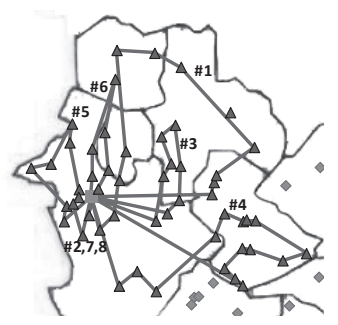

\begin{tabular}{|c|c|c|c|c|}
\hline Rota & Sequência de Visita & $\begin{array}{c}\text { Carga } \\
(\mathrm{kg})\end{array}$ & NoCont. & $\begin{array}{c}\text { Duração* } \\
(m)\end{array}$ \\
\hline \#1 & $191-123-126-127-138-136-141-140-144-143-153-154-191$ & 1.918 & 34 & 393 \\
\hline \#2 & $191-146-191$ & 1.975 & 23 & 235 \\
\hline \#3 & $191-149-147-133-134-135-131-132-148-191$ & 1.945 & 36 & 362 \\
\hline \#4 & $191-150-152-151-124-116-121-120-118-125-119-128-129-130-117-191$ & 1.734 & 38 & 398 \\
\hline \#5 & $191-156-167-166-165-159-160-161-162-157-155-191$ & 1.934 & 36 & 364 \\
\hline \#6 & $191-163-142-145-139-158-164-187-191$ & 1.993 & 38 & 384 \\
\hline \#7 & $191-185-191$ & 1.975 & 23 & 235 \\
\hline \multirow[t]{2}{*}{$\# 8$} & $191-186-191$ & 1.975 & 23 & 235 \\
\hline & Total & 15.450 & 251 & 2.606 \\
\hline
\end{tabular}

Figura 8: Rotas de recolha de papel no depósito de Abrantes

A solução obtida para este cenário implica 307 horas de trabalho para o depósito de Abrantes e 893 horas para o depósito de Avis, considerando apenas o número de horas necessárias às rotas de recolha e o respetivo tempo de descarga (excluiu-se o tempo relativo ao transporte secundário). Atendendo a que um motorista labora 210 horas no horizonte temporal considerado (35 horas/semana x 6 semanas) são necessários 2 motoristas para o depósito de Abrantes e 5 motoristas para o depósito de Avis. Quanto ao número de veículos e assumindo que cada veículo pode operar 378 horas em 6 semanas, é necessário pelo menos 1 veículo para o depósito de Abrantes e 3 veículos para o depósito de Avis. 
Os resultados computacionais do módulo 4 para este cenário são apresentados na Tabela 3. O limite máximo para o tempo de computação varia consoante a dificuldade em encontrar uma boa solução (com um gap reduzido ou idealmente de 0\%). Assim, no módulo 4, o tempo de computação é inicialmente limitado a 1 hora (3.600 s). Se o gap obtido for inferior ou igual a 5\% não é necessário aumentar o tempo de computação. Se o gap for superior a 5\% o tempo de computação é alterado para 4 horas (14.400 s) e a instância é resolvida novamente. Se a solução obtida ao fim de 4 horas apresentar um gap superior a 10\% então o limite máximo de computação é novamente aumentado, desta vez para 8 horas. As soluções encontradas apresentam um desvio entre a solução inteira e a solução linear relaxada (gap) de 1,4\% a 8\% tendo sido necessário entre 3.600 e 18.000 s para o seu processamento (os 18.000s incluem o tempo de execução de 3.600 s, em que se obteve um gap superior a 5\% e os seguintes $14.400 \mathrm{~s}$ em que se encontrou um gap inferior a 10\%).

Tabela 3: Resultados computacionais do módulo 4 no cenário 1

\begin{tabular}{|c|c|c|c|c|c|c|}
\hline \multirow[b]{2}{*}{ Material Reciclável } & \multicolumn{3}{|c|}{ Depósito Avis } & \multicolumn{3}{|c|}{ Depósito Abrantes } \\
\hline & $F O(\mathrm{~km})$ & Tempo (s) & Gap & $F O(\mathrm{~km})$ & Tempo (s) & Gap \\
\hline Papel & 8.393 & 18.000 & $4,3 \%$ & 4.328 & 18.000 & $3,6 \%$ \\
\hline Plástico/Metal & 7.672 & 18.000 & $3,7 \%$ & 4.421 & 3.600 & $1,4 \%$ \\
\hline Vidro & 2.643 & 18.000 & $8,0 \%$ & 1.942 & 18.000 & $6,1 \%$ \\
\hline
\end{tabular}

\subsubsection{Cenário 2: reestruturar as áreas de influência por material reciclável}

Neste cenário, os módulos 1, 2 e 4 do método híbrido foram executados de modo a construir as áreas de influência por material e as rotas de recolha associadas. Este cenário permite que, em cada local, cada material seja recolhido por depósitos diferentes. Assim, e dado existirem três materiais, cada depósito poderá ter três áreas de influência distintas.

O módulo 1 foi executado para cada material tendo-se obtido os resultados apresentados na Tabela 4. Para cada material identifica-se o número total de rotas abertas, o número de locais de recolha que pertencem às rotas abertas, o número de locais de recolha que foram afetos aos dois depósitos através das rotas fechadas e a distância total percorrida. De referir que o módulo 1 gerou 
rotas abertas para os materiais papel e vidro, não tendo sido gerada nenhuma para o material plástico/metal.

Tabela 4: Caracterização da solução obtida para o módulo 1 para cada material

\begin{tabular}{lcccccc}
\hline \multicolumn{1}{c}{ Material } & $\begin{array}{c}\text { Total } \\
\text { Rotas }\end{array}$ & $\begin{array}{c}\text { Rotas } \\
\text { Abertas }\end{array}$ & $\begin{array}{c}\text { Locais afetos às } \\
\text { Rotas Abertas }\end{array}$ & $\begin{array}{c}\text { Locais afetos ao } \\
\text { Dep. Avis }\end{array}$ & $\begin{array}{c}\text { Locais afetos ao } \\
\text { Dep. Abrantes }\end{array}$ & $\begin{array}{c}\text { Distância } \\
\text { Total (km) }\end{array}$ \\
\hline Papel & 33 & 2 & 23 & 134 & 21 & 10.817 \\
Plástico/Metal & 56 & 0 & 0 & 143 & 40 & 10.140 \\
Vidro & 28 & 4 & 28 & 139 & 7 & 3.600 \\
\hline
\end{tabular}

A título demonstrativo apresenta-se na Figura 9 a solução do módulo 1 para os materiais vidro e papel com a identificação das rotas abertas.

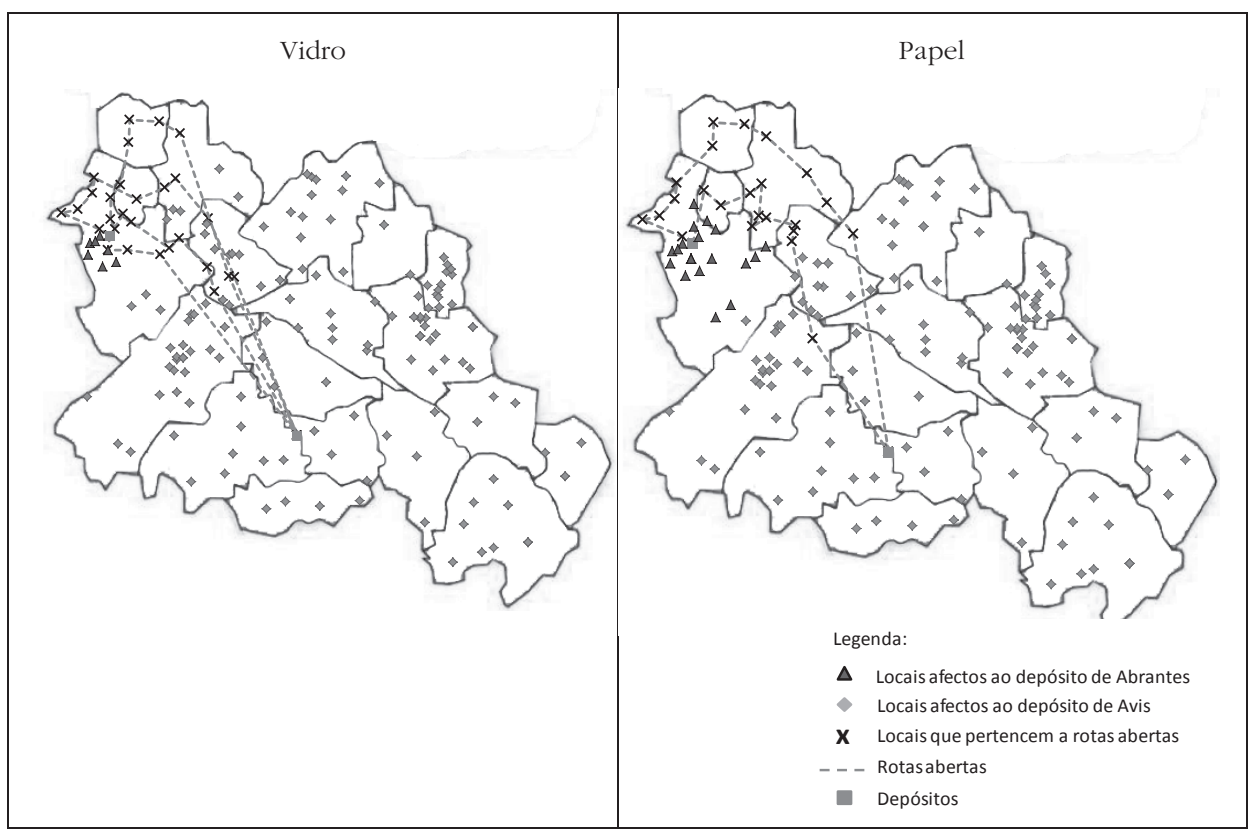

Figura 9: Solução do módulo 1 para os materiais vidro e papel

Dada a existência de rotas abertas para os materiais vidro e papel, o módulo 2 foi executado para estes materiais para cada rota aberta gerada (num total de 6). Dos resultados obtidos conclui-se que os locais de recolha pertencentes às quatro rotas abertas do material vidro foram todos afetos ao depósito de Avis, o que significa que este depósito fica responsável por 167 locais de recolha 
para o material vidro, restando apenas 7 para o depósito de Abrantes. No caso do papel, 12 locais de recolha foram afetos ao depósito de Abrantes e 11 ao depósito de Avis, totalizando os depósitos 33 e 145 locais, respetivamente. As áreas de influência finais por material reciclável estão representadas na Figura 10. Note-se que para o plástico/metal, as mesmas ficaram definidas logo no módulo 1.

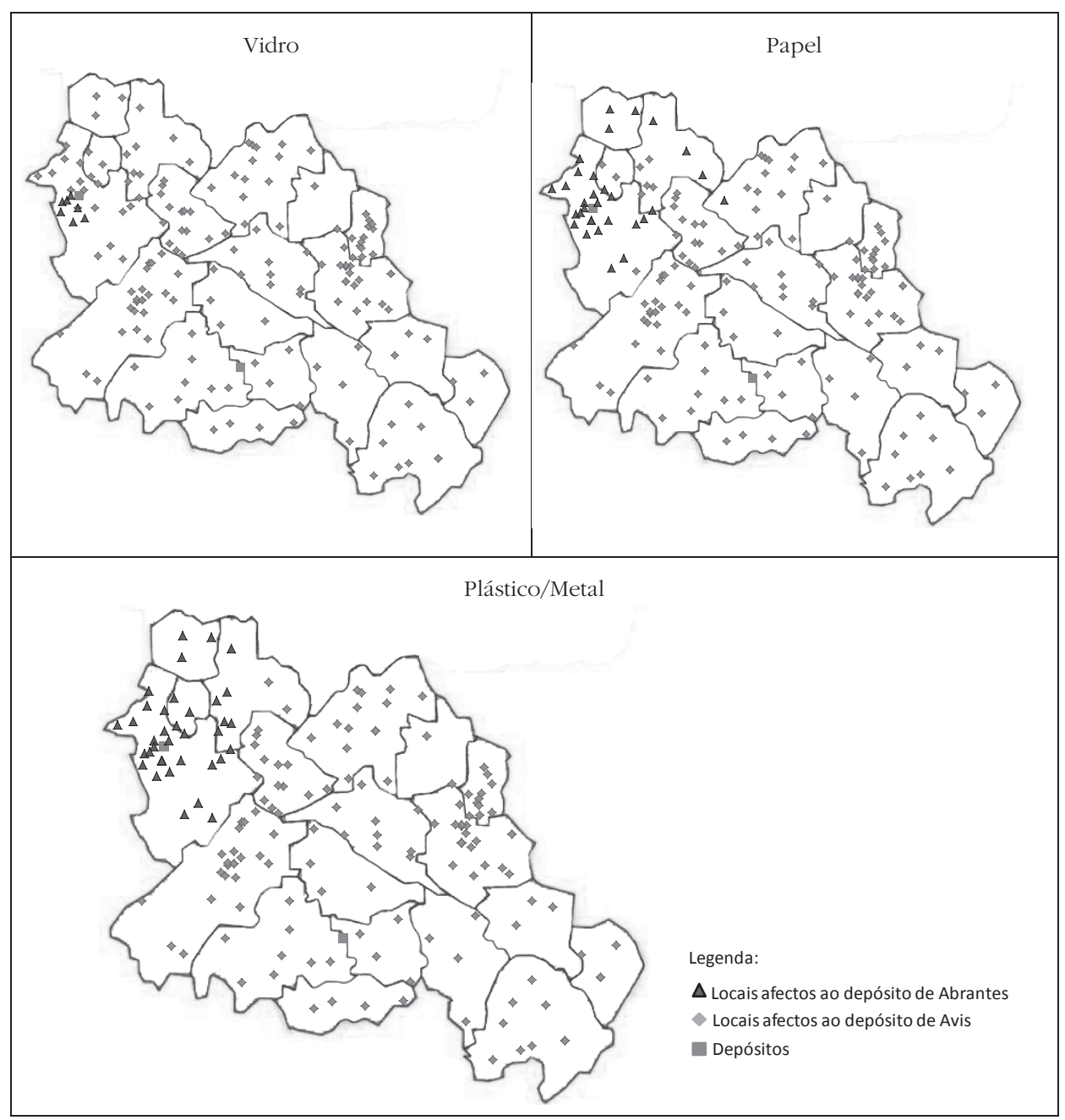

Figura 10: Áreas de influência por material no cenário 2 
Pela observação da Figura 10 constata-se que as áreas de influência são significativamente diferentes entre si. O depósito de Abrantes é apenas responsável por 7 locais de recolha para o vidro, sendo responsável por 33 locais para o papel e 40 para a recolha do plástico/metal.

Após a execução do módulo 4 obteve-se uma distância total percorrida de $24.802 \mathrm{~km}$ no horizonte temporal considerado (ver Figura 11). Comparando com o cenário 1, o depósito de Avis tem de percorrer mais 1.603 km (o que corresponde a um aumento de 9\%). Consequentemente, o depósito de Abrantes diminui a distância a percorrer em 58\%. A distância total percorrida diminui $16 \%$, tendo o transporte primário sido reduzido em $14 \%$ e o transporte secundário em $27 \%$.

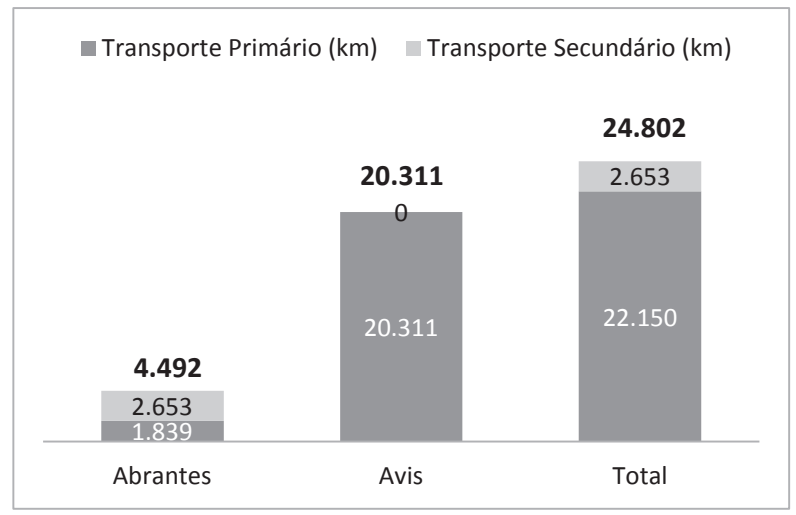

Figura 11: Distância total a percorrer por depósito no cenário 2

Este cenário envolve 1.009 horas de trabalho para o depósito de Avis e 167 horas para o depósito de Abrantes, o que corresponde a uma redução de 2\% no total de horas necessárias face ao cenário 1. Assim, são necessários pelo menos 6 motoristas e 4 veículos para operacionalizar esta solução.

Os resultados computacionais dos módulos 1 e 4 estão apresentados nas Tabelas 5 e 6, respetivamente. Como o módulo 1 lida com a instância de maior dimensão (uma vez que considera os 189 locais de recolha em simultâneo) e vai condicionar os resultados dos módulos seguintes, optou-se por alargar o tempo de computação a 8 horas $(28.800$ s) de forma a encontrar soluções mais próximas do ótimo. Assim, obtiveram-se soluções que apresentam um gap 
inferior a $5 \%$ ao fim de 8 horas de processamento. Relativamente ao módulo 2 , as 6 corridas realizadas (correspondente às 6 rotas abertas geradas pelo módulo 1) foram resolvidas até à otimalidade em menos de 1 minuto. O módulo 4 conseguiu provar a otimalidade em 3 instâncias e nas restantes 3 encontrou soluções com gaps entre 3,7\% e 9,1\%. Este último valor corresponde à instância de maior dimensão, com 167 locais de recolha.

Tabela 5: Resultados computacionais para o módulo 1 no cenário 2

\begin{tabular}{|c|c|c|c|}
\hline Material Reciclável & $F O(\mathrm{~km})$ & Tempo (s) & Gap \\
\hline Papel & 10.817 & 28.800 & $4,9 \%$ \\
\hline Plástico/Metal & 10.140 & 28.800 & $3,3 \%$ \\
\hline Vidro & 3.600 & 28.800 & $4,5 \%$ \\
\hline
\end{tabular}

Tabela 6: Resultados computacionais para o módulo 4 no cenário 2

\begin{tabular}{|c|c|c|c|c|c|c|}
\hline \multirow[b]{2}{*}{ Material Reciclável } & \multicolumn{3}{|c|}{ Depósito Avis } & \multicolumn{3}{|c|}{ Depósito Abrantes } \\
\hline & $F O(\mathrm{~km})$ & Tempo (s) & Gap & $F O(\mathrm{~km})$ & Tempo (s) & Gap \\
\hline Papel & 8.968 & 18.000 & $8,3 \%$ & 2.070 & 22 & $0,0 \%$ \\
\hline Plástico/Metal & 7.977 & 3.600 & $3,7 \%$ & 2.163 & 43 & $0,0 \%$ \\
\hline Vidro & 3.366 & 18.000 & $9,1 \%$ & 259 & 1 & $0,0 \%$ \\
\hline
\end{tabular}

\subsubsection{Cenário 3: reestruturar as áreas de influência por depósito}

Neste cenário, dado que se pretende definir áreas de influência por depósito, todos os módulos do método híbrido proposto foram executados. A solução final contempla apenas uma área de influência para cada depósito, comum a todos os materiais.

As soluções obtidas para os módulos 1 e 2 são comuns às do cenário anterior, pelo que para este cenário apenas foi necessário executar o módulo 3 antes do módulo 4. Sobrepondo as três áreas de influência obtidas no cenário 2 (Figura 12), observa-se que 32 locais de recolha estão na situação designada de "indecisos", ou seja, pertencem a depósitos diferentes consoante o material a recolher.

Estes 32 locais de recolha "indecisos" com os três materiais são o input do módulo 3, onde uma formulação em PLIM para o MP-MDVRP é resolvida, 
impondo-se que todos os materiais de um mesmo local pertençam ao mesmo depósito. Como resultado, os 32 locais de recolha foram afetos ao depósito de Abrantes. Assim, este depósito fica responsável por 43 locais de recolha e o depósito de Avis por 146. As áreas de influência finais para o cenário 3 são apresentadas na Figura 13.

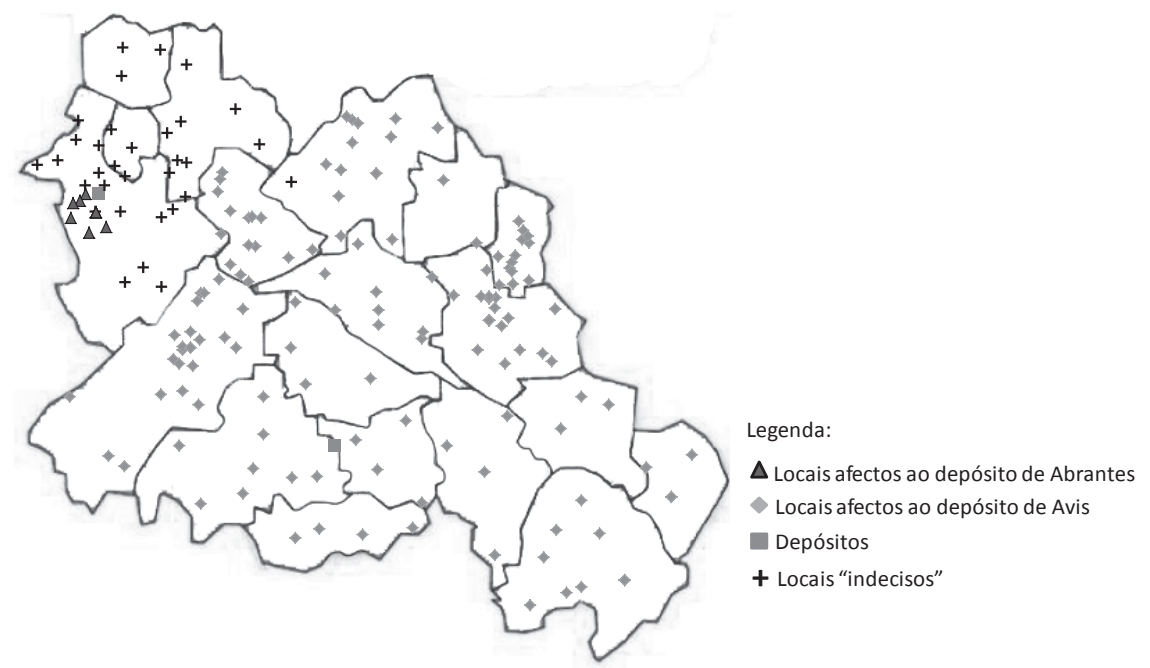

Figura 12: Resultado da sobreposição das três áreas de influência do cenário 2

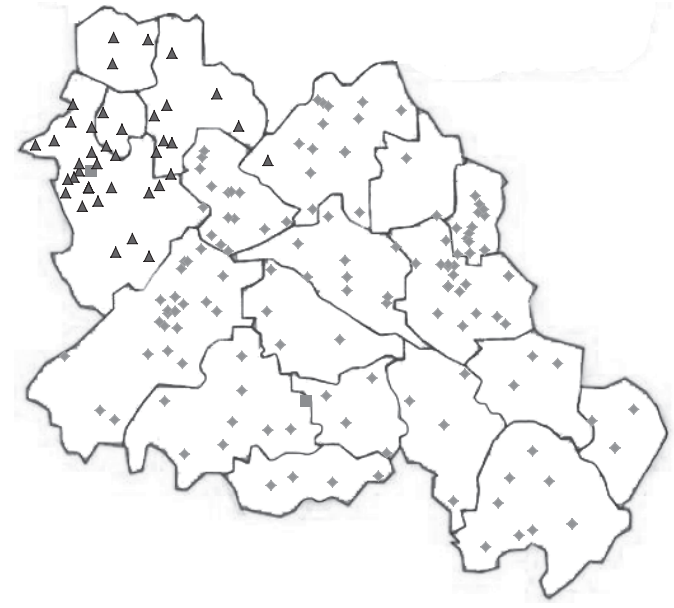

Legenda:

$\Delta$ Locais afectos ao depósito de Abrantes Locais afectos ao depósito de Avis Depósitos

Figura 13: Áreas de influência por depósito no cenário 3 
A solução proposta para o cenário 3 implica uma distância total percorrida de $25.290 \mathrm{~km}$ (ver Figura 14). Isto significa que uma reestruturação das áreas de influência por depósito permite uma redução de 14\% no total da distância a percorrer face às atuais áreas de influência (cenário 1).

Relativamente às horas de trabalho, este cenário envolve um total de 1.165 horas, repartidas por 213 horas para o depósito de Abrantes e 952 horas para o depósito de Avis. Tal como no cenário anterior, são necessários pelo menos 6 motoristas e 4 veículos.

A Tabela 7 apresenta os resultados computacionais para o módulo 4. Novamente é no depósito de Avis e para os materiais papel e vidro que se verificam os maiores gaps, mesmo com um tempo computacional de 8 horas (os tempos de computação apresentados na Tabela 7 consideram os tempos que não permitiram obter um gap satisfatório). Estas são, como já foi referido, as instâncias de maior dimensão. Relativamente ao módulo 3, o problema com os 32 locais de recolha foi repartido em cinco instâncias, todas elas resolvidas até à otimalidade em menos de 1 minuto.

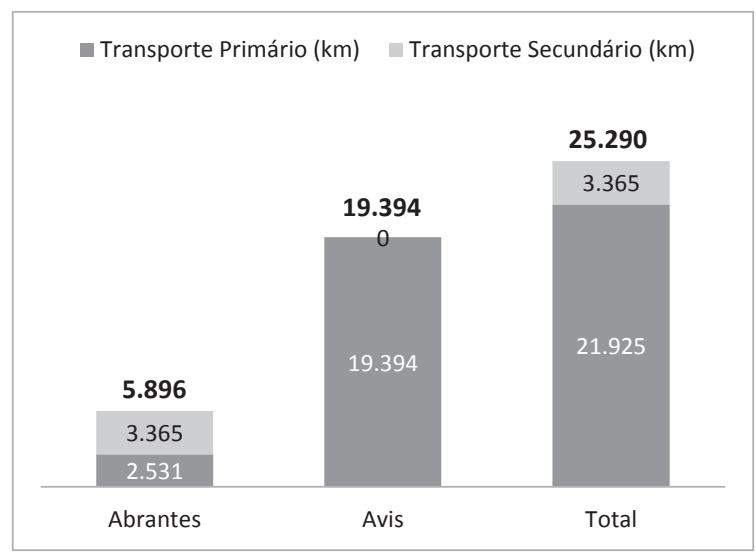

Figura 14: Distância total a percorrer por depósito no cenário 3

Tabela 7: Resultados computacionais para o módulo 4 no cenário 3

\begin{tabular}{|c|c|c|c|c|c|c|}
\hline \multirow[b]{2}{*}{ Material Reciclável } & \multicolumn{3}{|c|}{ Depósito Avis } & \multicolumn{3}{|c|}{ Depósito Abrantes } \\
\hline & $F O(\mathrm{~km})$ & Tempo (s) & Gap & $F O(\mathrm{~km})$ & Tempo (s) & Gap \\
\hline Papel & 8.693 & 46.800 & $8,4 \%$ & 2.422 & 565 & $0,0 \%$ \\
\hline Plástico/Metal & 7.923 & 3.600 & $3,7 \%$ & 2.275 & 53 & $0,0 \%$ \\
\hline Vidro & 2.779 & 46.800 & $9,7 \%$ & 1.200 & 3.600 & $1,8 \%$ \\
\hline
\end{tabular}




\section{Discussão Final}

O objetivo deste trabalho prende-se com a utilização de técnicas de Investigação Operacional de forma a encontrar melhores soluções para o sistema de recolha de resíduos de embalagens gerido pela Valnor. Entre as várias abordagens possíveis para a resolução deste caso (abordagens exatas, heurísticas ou híbridas) optou-se por uma abordagem híbrida, em que o problema original modelado como um Multi-Product, Multi-Depot Vebicle Routing Problem é decomposto em quatro sub-problemas, sendo cada um modelado através de uma formulação PLIM.

A aplicação do método proposto exigiu uma extensa análise e tratamento dos dados de forma a extrair os necessários para alimentar o modelo. Por outro lado, em aplicações reais de problemas de definição de rotas de veículos é impreterível fornecer ao modelo as distâncias reais, o que exige a utilização de um sistema de informação geográfica capaz de construir uma matriz distância de dimensão elevada.

A aplicação do método ao caso Valnor permitiu encontrar soluções mais vantajosas face à situação atualmente implementada, onde são percorridos cerca de $31.000 \mathrm{~km}$ no horizonte temporal de 6 semanas (ver Figura 15).

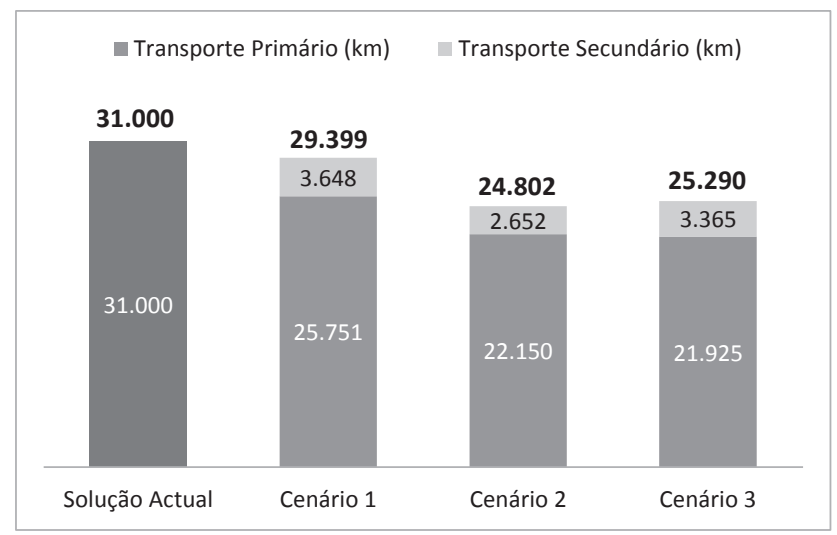

Figura 15: Comparação da distância percorrida nos cenários estudados

Optando por um cenário mais conservador (cenário 1) em que se mantêm as atuais áreas de influência dos dois depósitos, a Valnor conseguirá uma redução de cerca de 5\% no total da distância percorrida, se proceder apenas ao 
reprojeto e otimizacão das rotas de recolha. Esta solução representa uma alteração nos circuitos atualmente em vigor e na periodicidade dos mesmos. Será, portanto, a alteração onde deverão existir menos barreiras à sua implementação dado que necessitará apenas de formar os motoristas para novos circuitos de recolha. A taxa de utilização agregada para o número mínimo de veículos necessários para esta solução é de 81\% para Abrantes e 79\% para Avis (considerando o número de horas de trabalho versus número de horas disponíveis).

Optando por um cenário intermédio, em que as áreas de influência são reestruturadas, mantendo-se a recolha de todos os materiais de um mesmo local da responsabilidade de um único depósito (cenário 3), é possível obter, face à solução atual, uma redução de 18\% na distância total a percorrer, o que se refletirá diretamente numa redução dos custos operacionais. Neste cenário, um maior número de locais de recolha são afetos ao depósito de Avis (146 contra 132 na situação atual) que opera também como estação de triagem. Assim, neste cenário existe uma redução tanto no transporte primário como no transporte secundário. Face ao cenário 1, a reestruturação das áreas de influência por depósito (cenário 3) gera uma poupança total de 14\%. A solução do cenário 3 implica uma alteração das áreas de influência atuais, transferindose locais de recolha que atualmente são da responsabilidade de Abrantes para Avis. Esta transferência implica um aumento da carga de trabalho de Avis, resultando num aumento da taxa de utilização dos veículos para 89\% e numa diminuição da taxa de utilização de Abrantes para 44\%. Ao contrário do cenário 1, o cenário 3 apresenta taxas de utilização dos veículos mais desequilibradas entre depósitos. No entanto, os ganhos relativos à redução da distância total a percorrer são significativos.

O cenário mais afastado da situação atual é aquele em que a lógica da definição das áreas de influência é mais alterada, levando a que cada depósito tenha de gerir três áreas diferentes, uma por cada material (cenário 2). Este é o cenário com a menor distância a percorrer, reduzindo em 20\% o valor atualmente verificado. Comparando os cenários 2 e 3, o primeiro implica uma distância menor em apenas $2 \%$ face ao último, mas envolve uma mudança mais complexa na gestão das operações no sistema em causa. Por outro lado, esta 
solução implica que o sistema de informação de recolha de dados esteja integrado entre depósitos. Note-se que atualmente quando um contentor de um material é recolhido, é registada informação sobre a taxa de enchimento dos restantes contentores que compõe um ecoponto (um ecoponto é constituído por três contentores, um para cada material). Como neste cenário o depósito que visita um tipo de material pode não ser o mesmo que visita os restantes materiais, se o sistema de informação de dados não estiver integrado entre depósitos, perder-se-á informação sobre as taxas de enchimento reais. Esta informação é essencial para se poder replanear as rotas em caso de observação de situações atípicas. No cenário 2 , as taxas de utilização para o número mínimo de veículos é de 56\% para Abrantes e 84\% para Avis, existindo um desequilíbrio menor entre depósitos do que o observado no cenário 3.

Como trabalho futuro pretende-se adicionar um módulo de calendarização das rotas ao método proposto. Uma vez que as rotas estão definidas, para operacionalizar a solução encontrada é necessário definir o dia em que cada uma irá ocorrer, garantindo a frequência de recolha definida e minimizando o número de veículos e motoristas. Por outro lado, dever-se-á estudar a robustez das áreas de influência propostas face ao aumento das quantidades a recolher, quer devido à sazonalidade, quer ao aumento da consciencialização das populações para a reciclagem, o que gerará maiores quantidades depositadas nos contentores.

Por último, a Valnor encontra-se neste momento num processo de alargamento da sua área de abrangência, tendo integrado recentemente seis novos concelhos: Castelo Banco, Idanha-a-Nova, Oleiros, Sertã, Proença-a-Nova e Vila Velha de Rodão. Neste sentido, será necessário estudar esta nova realidade que passará por, numa primeira fase, definir as rotas para estes novos concelhos a partir do novo depósito de Castelo Branco e, numa segunda fase, estudar uma solução integrada para os 25 concelhos e 3 depósitos.

Como comentário final é importante notar como a aplicação de metodologias de Investigação Operacional contribuiu para a resolução de um conjunto de problemas que se colocam à Valnor, permitindo encontrar e comparar soluções alternativas à situação atual que melhoram a sua performance operacional. Por outro lado, as ferramentas desenvolvidas são 
suficientemente genéricas, o que permite a sua aplicação a outros casos com características semelhantes, contribuindo assim para melhorar a eficiência em outros sistemas de recolha de resíduos de embalagens.

\section{BIBIOGRAFIA}

ARCGIS, 2011. http://www.arcgis.com, consultada em Fevereiro 2011.

BALDACCI, R., HADJICONSTANTINOU, E. e MINGOZZI, A. 2004. An exact algorithm for the capacitated vebicle routing problem based on a two-commodity network flow formulation. Operations Research, 52, 723-738.

BALDACCI, R. e MINGOZZI, A. 2009. A unified exact method for solving different classes of vehicle routing problems. Mathematical Programming, 120, 347-380.

BETTINELLI, A., CESELLI, A. e RIGHINI, G. 2011. A branch-and-cut-and-price algorithm for the multi-depot heterogeneous vehicle routing problem with time windows. Transportation Research Part C-Emerging Technologies, 19, 723-740.

CREVIER, B., CORDEAU, J. F. e LAPORTE, G. 2007. The multi-depot vebicle routing problem with inter-depot routes. European Journal of Operational Research, 176, 756-773.

GOLDEN, B. L., MAGNANTI, T. L. e NGUYEN, H. Q. 1977. Implementing Vehicle Routing Algorithms. Networks, 7, 113-148.

HADJICONSTANTINOU, E. \& BALDACCI, R. 1998. A multi-depot period vehicle routing problem arising in the utilities sector. Journal of the Operational Research Society, 49, 1239-1248.

HO, W., HO, G. T. S., JI, P. \& LAU, H. C. W. 2008. A bybrid genetic algorithm for the multidepot vehicle routing problem. Engineering Applications of Artificial Intelligence, 21, 548-557.

ILOG-CPLEX, 2011. http://www-01.ibm.com/software/integration/optimization/cplex-optimizer/, consultada em Fevereiro 2011.

INSTITUTO NACIONAL DE eSTATístiCA, 2010. Gestão dos Resíduos em Portugal 2004-2009. http://www.ine.pt, consultada em Agosto 2010.

LAPORTE, G. 1992. The Vehicle-Routing Problem - an Overview of Exact and Approximate Algorithms. European Journal of Operational Research, 59, 345-358.

LAPORTE, G., NOBERT, Y. e ARPIN, D. 1984. Optimal solutions to capacitated multi-depot vehicle routing problems. Congressus Numerantium, 44, 283-292.

LAPORTE, G., NOBERT, Y. e TAILlEFER, S. 1988. Solving a Family of Multi-Depot VehicleRouting and Location-Routing Problems. Transportation Science, 22, 161-172.

LIM, A. \& WANG, F. 2005. Multi-depot vebicle routing problem: A one-stage approach. Ieee Transactions on Automation Science and Engineering, 2, 397-402.

PARTHANADEE, P. e LOGENDRAN, R. 2006. Periodic product distribution from multi-depots under limited supplies. IIE Transactions, 38, 1009-1026.

PISINGER, D. e ROPKE, S. 2007. A general heuristic for vebicle routing problems. Computers \& Operations Research, 34, 2403-2435.

RENAUD, J., LAPORTE, G. \& BOCTOR, F. F. 1996. A tabu search heuristic for the multi-depot vehicle routing problem. Computers \& Operations Research, 23, 229-235.

SALHI, S. e SARI, M. 1997. A multi-level composite heuristic for the multi-depot vehicle fleet mix problem. European Journal of Operational Research, 103, 95-112. 
TILLMAN, F. A. e CAIN, T. M. 1972. Upperbound Algorithm for Single and Multiple Terminal Delivery Problem. Management Science Series a-Theory, 18, 664-682.

VIDAL, T., CRAINIC, T. G., GENDREAU, M., LAHRICHI, N. e REI, W. 2012. A Hybrid Genetic Algorithm for Multidepot and Periodic Vehicle Routing Problems. Operations Research, 60, 611-624. 